\title{
Molecular Dynamics Investigation of Surface Resistances in Zeolite Nanosheets
}

\author{
Omar Knio, Hanjun Fang, Salah Eddine Boulfelfel, Sankar Nair, David S. Sholl
}

School of Chemical \& Biomolecular Engineering, Georgia Institute of Technology, 311 Ferst Drive NW, Atlanta, GA 30332-0100

CORRESPONDING AUTHOR: david.sholl@ chbe.gatech.edu

\section{Table of Contents}

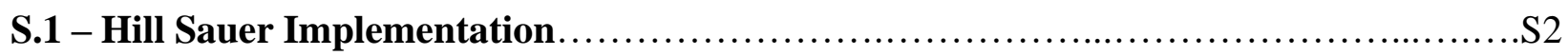

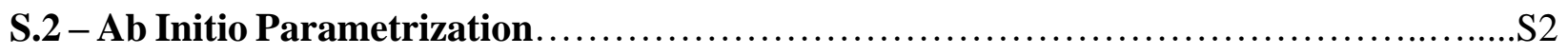

S.3 - Hydrocarbon Lennard-Jones Parameters...........................................

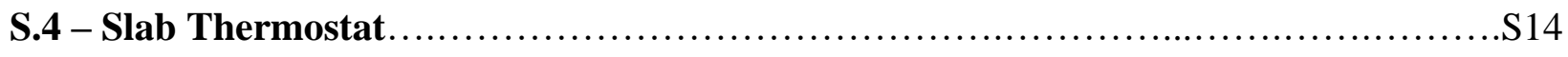

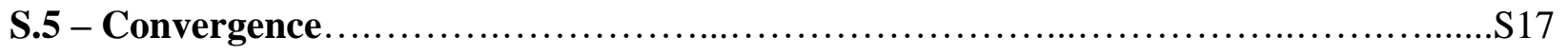

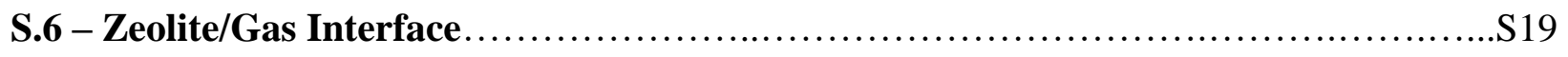

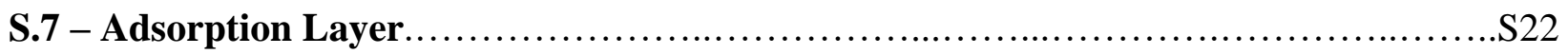

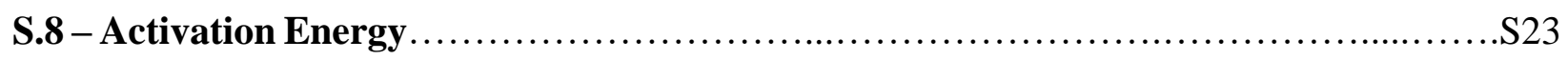

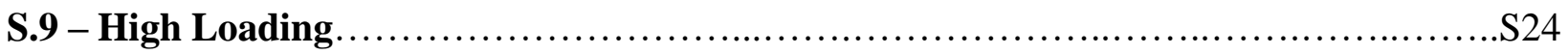

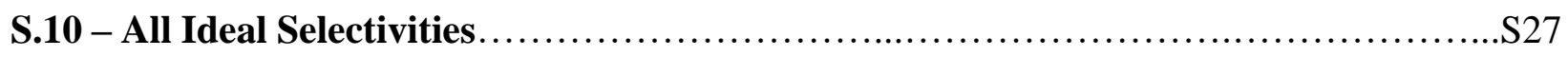

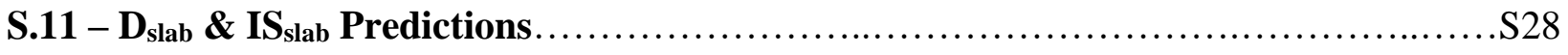

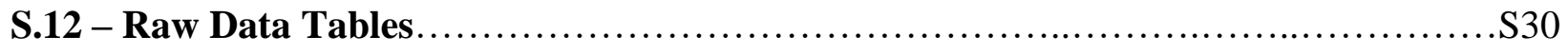

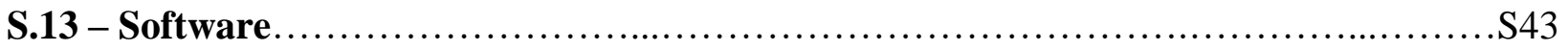

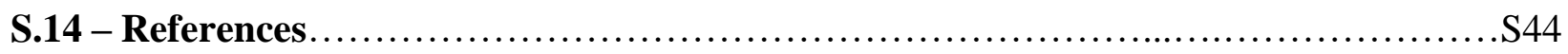




\section{S.1 Hill Sauer Implementation}

Boulfelfel et al. modified the Hill Sauer force field for a better description of zeolite pore dimensions. ${ }^{1}$ They changed the equilibrium angle of the Si-O-Si and O-Si-O terms while keeping all other parameters constant. ${ }^{1}$ The Hill-Sauer FF uses LAMMPS' Class 2 angle terms with the format

$$
\begin{aligned}
& E=K_{2}\left(\theta-\theta_{0}\right)^{2}+K_{3}\left(\theta-\theta_{0}\right)^{3}+K_{4}\left(\theta-\theta_{0}\right)^{4}+M\left(r_{i j}-r_{1}\right)\left(r_{j k}-r_{2}\right)+ \\
& N_{1}\left(r_{i j}-r_{1}\right)\left(\theta-\theta_{0}\right)+N_{2}\left(r_{j k}-r_{2}\right)\left(\theta-\theta_{0}\right)
\end{aligned}
$$

where $\mathrm{i}-\mathrm{j}-\mathrm{k}$ refer to the order of the three atoms, $K, M$, and $N$ are energy scalars, $\theta_{0}$ is the equilibrium angle, $\theta$ is the angle between the three atoms, $r_{1}$ and $r_{2}$ are the equilibrium bond distances between atoms $\mathrm{i}-\mathrm{j}$ and $\mathrm{j}-\mathrm{k}$ respectively, $r_{i j}$ and $r_{j k}$ are the bond distances between atoms $\mathrm{i}-\mathrm{j}$ and $\mathrm{j}-\mathrm{k}$ respectively. ${ }^{2}$ Boulfelfel et al. only changed the $\theta_{0}$ terms for both angles and kept all other distance and scalar terms at their original values. ${ }^{1}$ The Boulfelfel et al. terms used in this study and the original terms are shown in Table $\mathbf{S . 1}$ for comparison.

Table S.1 - Equilibrium Angle Comparisons

\begin{tabular}{lcc}
\hline & Si-O-Si & O-Si-O \\
\hline$\theta_{0}-$ Original Hill-Sauer $^{3}$ & 173.7651 & 112.0200 \\
$\theta_{0}-$ Boulfefel et al. $^{4}$ & 150.0 & 113.0
\end{tabular}

There are other parameters in the Hill-Sauer force field that use the Si-O-Si and O-Si-O $\theta_{0}$ such as dihedral and improper terms. However, Boulfelfel et al. kept the original Hill-Sauer $\theta_{0}$ for the angle component of these terms, so we followed their example in our work as well. ${ }^{3}$

\section{S.2 DFT-derived Force Field Parametrization for $\mathrm{CO}_{2}$ and $\mathrm{H}_{2}$}

Fang et al. developed a first-principles-based force field for $\mathrm{CO}_{2}$ in siliceous zeolites that showed good transferability across different zeolite topologies. ${ }^{5}$ This approach 
used the fully periodic framework to represent the adsorbent structure and relies on electronic structure calculations for hundreds or thousands of adsorption configurations randomly scattered throughout the framework. This approach was later extended to develop parameters for $\mathrm{CH}_{4}$ in siliceous zeolites that can accurately predict both adsorption and diffusion properties. ${ }^{6}$ In those studies, the charges for $\mathrm{CH}_{4}$ and zeolite atoms were obtained from the density derived electrostatic and chemical (DDEC) method while the charges for $\mathrm{CO}_{2}$ were obtained from the EPM2 model. ${ }^{7-}$

${ }^{10}$ In this manuscript, we developed first-principles-based force fields for $\mathrm{CO}_{2}$ and $\mathrm{H}_{2}$ in bulk and nanosheet siliceous zeolites that use atomic charges from the Hill Sauer force field, since these charges are quite different than DDEC charges. ${ }^{11,12}$ We used the EPM2 model for $\mathrm{CO}_{2} \ldots \mathrm{CO}_{2}$ interactions; this model correctly captures the phase behavior of pure $\mathrm{CO}_{2}{ }^{10} \mathrm{H}_{2} \ldots \mathrm{H}_{2}$ interactions were treated as a three-point model used previously by Yang et al. ${ }^{13}$

\section{S.2.1 Generating Training Sets for Force Field Fitting}

The first step in force field fitting is the generation of a training set of atomic coordinates that adequately samples the potential energy surface. We generated one training set to describe adsorbate interactions with the bulk zeolite ( $\left.\mathrm{Si}, \mathrm{O}_{\mathrm{SiOSi}}\right)$ using biased molecular dynamics (MD) and another training set to describe adsorbate interactions with the hydrogen of silanol groups (Нон) using Grand Canonical Monte Carlo (GCMC). The biased MD method is useful for deriving a force field that is accurate for both adsorption and diffusion properties because it generates adsorbate configurations in both pore and cage regions. ${ }^{6}$

We generated bulk zeolite adsorbate coordinates using half the cage volume of Zeolite A (LTA) as shown in Figure S.1. We divided this volume into six bins with equal width $(1 \AA$ ) parallel to the 8-ring plane. In each bin we performed a biased NVT molecular dynamics (MD) simulation for 200 ps after an equilibration period of 100 ps. Each simulation had one adsorbate and used a 
time step of 1 fs. Configurations were collected every 0.5 ps for a total of 2400 (400 from each bin). We used biased molecular dynamics to ensure that adsorbates remain inside their cage so that our configuration sample is representative. An unconstrained adsorbate will likely oversample the cage and undersample the transition state region. We confined each adsorbate near to its bindefining plane with a harmonic spring constant of $15 \mathrm{kcal} / \mathrm{mol}$ using the COLVARS package ${ }^{14}$ from LAMMPS ${ }^{15}$. In all biased MD simulations, the adsorbent atoms were fixed and only the adsorbate was allowed to move. The force field we used for the initial simulation was derived from Grimme's empirical dispersion expression in the DFT-D2 method,

$$
C_{6}^{i j}=4 \varepsilon_{i j} \sigma_{i j}^{6} \text { and } C_{12}^{i j}=\frac{\left(R_{0}^{i}+R_{0}^{j}\right)^{6}}{2} C_{6}^{i j}=4 \varepsilon_{i j} \sigma_{i j}^{12}
$$

where $R_{0}^{i}$ and $R_{0}^{j}$ are the Van der Waals radii of each atom. ${ }^{16}$ Grimme's work lists parameters for $C_{6}$ and $R_{0}$ for elements from $\mathrm{H}$ to $\mathrm{Xe} .{ }^{16}$ The $C_{6}^{i j}$ term is defined as

$$
C_{6}^{i j}=\sqrt{C_{6}^{i} C_{6}^{j}}
$$

where the superscripts refer to the element described by $C_{6} \cdot{ }^{16}$ Solving equation S.2 gives $\varepsilon_{i j}$ and $\sigma_{i j}$. The $\varepsilon_{i j}$ and $\sigma_{i j}$ terms are used to calculate the van der Waals energy in our MD simulations using the 12-6 form of the Lennard-Jones equation

$$
E_{v d W}=E_{\text {Lennard-Jones }}=4 \varepsilon_{i j}\left[\left(\frac{\sigma_{i j}}{r}\right)^{12}-\left(\frac{\sigma_{i j}}{r}\right)^{6}\right]
$$

where $r$ is the distance between both atoms. 
(a)

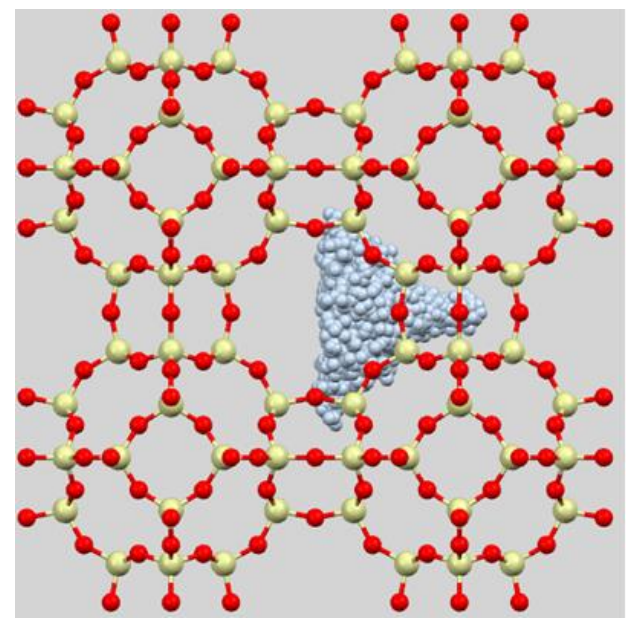

(b)

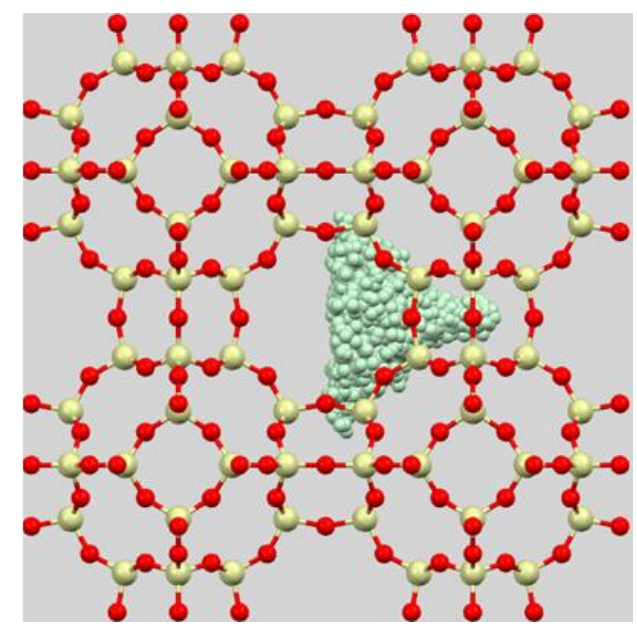

Figure S.1. Illustration of the training sets used to fit force field parameters for (a) $\mathrm{CO}_{2}$-framework and (b) $\mathrm{H}_{2}$-framework interactions based on a bulk siliceous zeolite, $\mathrm{Si}$-LTA. O, $\mathrm{Si}, \mathrm{CO}_{2}$ and, $\mathrm{H}_{2}$ atoms are depicted as red, beige, blue and green respectively.

To make training sets for $\mathrm{CO}_{2}$ and $\mathrm{H}_{2}$ interactions with the hydrogen of the surface hydroxyl group ( $\mathrm{HoH})$ on zeolite surfaces, we generated initial configurations using NVT Monte Carlo $(\mathrm{N}=1, \mathrm{~T}=300 \mathrm{~K})$ on $9 \AA \mathrm{CHA}(101)$ nanosheets. We used the force field parameters derived from the bulk zeolites to define interactions with the $\mathrm{Si}, \mathrm{O}_{\mathrm{SiOSi}}$, and $\mathrm{O}_{\mathrm{SiOH}}$ atoms. The van der Waals (vdW) parameters for the oxygen atom of the hydroxyl group were assumed to be equivalent to those for framework oxygen atoms. The initial $\mathrm{HoH}$ parameters were obtained from Grimme's empirical dispersion expression in the DFT-D2 method. ${ }^{16}$ Based on the simulation snapshots, 800 configurations were randomly chosen as shown in Figure S.2. 
(a)

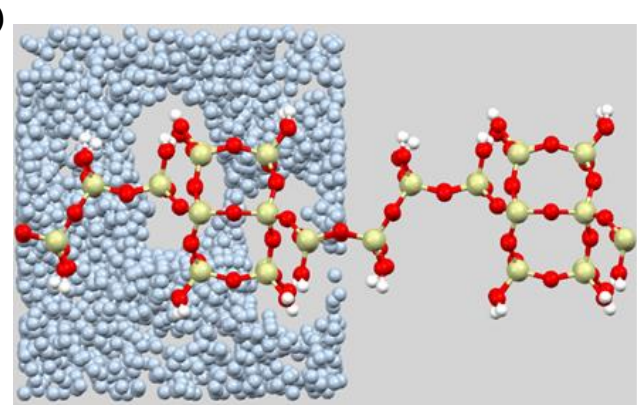

(b)

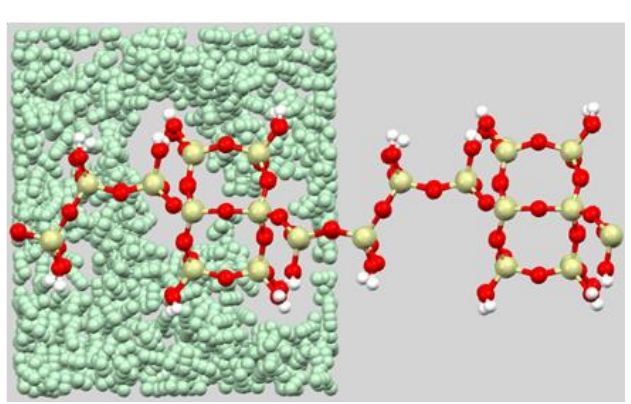

Figure S.2: Illustration of the training sets used to fit force field parameters for (a) $\mathrm{CO}_{2}$-hydroxyl and (b) $\mathrm{H}_{2}$-hydroxyl interactions based on a two-dimensional chabazite nanosheet. $\mathrm{O}, \mathrm{Si}, \mathrm{H}, \mathrm{CO}_{2}$ and, $\mathrm{H}_{2}$ atoms are depicted as red, beige, white, blue and green respectively.

\section{S.2.2 Adsorbate Zeolite Interactions}

After the training sets above were generated, our next step was to compute PBE DFT adsorbate-adsorbent interaction energies defined as:

$$
E_{\text {interaction }}^{\text {DFT }}=E_{\text {adsorbate,zeolite }}-\left(E_{\text {adsorbate }}-E_{\text {zeolite }}\right)
$$

For each configuration, the total energy of the system (adsorbate + adsorbent) was calculated, then the energies of the empty adsorbent and isolated adsorbate were subtracted to obtain the corresponding interaction energy. All DFT single-point calculations were performed using VASP package $^{17-20}$ version 5.4.4 in combination with projector augmented wave (PAW) pseudopotentials. ${ }^{21,22}$ A plane-wave basis set energy cut-off equal to $520 \mathrm{eV}$ was used. Gaussian electronic smearing with width equal to $0.2 \mathrm{eV}$ was applied. A Blocked Davidson electronic minimization algorithm was used to calculate the electronic ground state, with convergence stopping criterion set to $10^{-4} \mathrm{eV}$. It has been shown that dispersion corrections are important for accurately describing interactions between adsorbate molecules and zeolites, and the DFT/CC (density functional theory/coupled cluster) method performs well for these system, ${ }^{5}$, ${ }^{23}$ so the $\mathrm{CC}$ corrections that were developed previously for adsorption of $\mathrm{CO}_{2}$ and $\mathrm{H}_{2}$ in zeolites were added to the PBE interaction energies. ${ }^{24,25}$ 
The electrostatic part of the interaction energy was independently computed for each configuration using Ewald summation. After computing $E_{\text {interaction }}^{D F T / C C}$ and $E_{\text {Coulomb }}^{F F}$, the fitting itself involved least-squares regression to determine new values for $C_{6}^{i j}$ and $C_{12}^{i j}$ in equation S.6.

$$
E_{v d W}\left(R_{i j}\right)=E_{\text {Lennard-Jones }}\left(R_{i j}\right)=\frac{C_{12}^{i j}}{R_{i j}^{12}}-\frac{C_{6}^{i j}}{R_{i j}^{6}}
$$

To calculate bulk parameters, we fitted equation S.6 to 2400 configurations then used the bulk parameters in the next iteration of the biased NVT MD simulations. This procedure was performed for 3-6 iterations until the fitted force field parameters were converged (the changes of parameters are within $\pm 3 \%$ ). For nanosheets, we were unable to obtain complete convergence of the potential parameters (i.e. all parameter value's $\Delta<3 \%$ ) after six iterations, so we chose to use the configurations from last three iterations to finalize force field parameters. The resulting force field (denoted $\mathrm{CCFF}$ ) parameters for $\mathrm{CO}_{2}$ and $\mathrm{H}_{2}$ in bulk siliceous zeolites and zeolite nanosheets are summarized in Table S.2. 
Table S.2: $\mathrm{CO}_{2}$ and $\mathrm{H}_{2}$ Self Interaction and Zeolite Interaction Parameters

\begin{tabular}{|c|c|c|c|c|}
\hline Self Interaction & Reference & $\boldsymbol{\epsilon} / \mathbf{k}_{\mathrm{B}}(\mathbf{K})$ & $\sigma(\AA)$ & Charge (e) \\
\hline $\bar{C}$ _CO2 & $\overline{10}$ & 28.129 & 2.757 & 0.6512 \\
\hline O_CO2 & 10 & 80.507 & 3.033 & -0.3256 \\
\hline H_H2 & 26 & NA & NA & 0.468 \\
\hline c_-H2 & 26 & 36.7 & 2.96 & -0.936 \\
\hline \multicolumn{2}{|c|}{$\mathrm{C}=\mathrm{O}$ bond $1.149(\AA)^{10}$} & \multicolumn{3}{|c|}{ H-H bond $0.74(\AA)^{26}$} \\
\hline \multicolumn{5}{|l|}{ Hill-Sauer Charge } \\
\hline $\mathrm{Si}$ & 3 & & & 0.5236 \\
\hline $\mathrm{Oz}\left(\mathrm{O}_{\mathrm{SiOSi}}\right)$ & 3 & & & -0.2618 \\
\hline $\mathrm{Oz}\left(\mathrm{O}_{\mathrm{SiOH}}\right)$ & 3 & & & -0.195 \\
\hline $\mathrm{H}(\mathrm{Hон})$ & 3 & & & 0.0641 \\
\hline
\end{tabular}

\begin{tabular}{cccc}
\hline $\mathrm{CO}_{2}$ Cross Species & & & \\
\hline C_CO2 $-\mathrm{Oz}$ & This work & 28.610 & 3.016 \\
O_CO2-Oz & This work & 35.549 & 3.140 \\
C_CO2 $-\mathrm{Si}$ & This work & 60.747 & 3.560 \\
O_CO2 $-\mathrm{Si}$ & This work & 47.494 & 3.436 \\
C_CO2 $-\mathrm{Hz}$ & This work & 50.515 & 2.424 \\
O_CO2 $-\mathrm{Hz}$ & This work & 42.073 & 2.316 \\
\hline
\end{tabular}

\begin{tabular}{cccc}
\hline $\mathbf{H}_{2}$ Cross Species & & & \\
\hline c_H2 $-\mathrm{Oz}$ & This work & 31.726 & 2.971 \\
c_H2 $-\mathrm{Si}$ & This work & 47.376 & 3.446 \\
c_H2 $-\mathrm{Hz}$ & This work & 19.213 & 2.348 \\
$\mathrm{H} \_\mathrm{H} 2-$ All atoms & & NA & NA
\end{tabular}

\section{S.2.3 Force Field Analysis}

In the FF fitting, the residual standard deviation (RSD) is minimized,

$$
R S D=\sqrt{\frac{\sum_{k}^{n}\left(E_{F F}^{k}-E_{D F T / C C}^{k}\right)^{2}}{n-2}}
$$

where $E_{F F}^{k}$ is the interaction energy calculated at the $\mathrm{FF}$ level for configuration $k, E_{D F T / C C}^{k}$ is the interaction energy calculated at the DFT/CC level, and $n$ is the number of configurations for our FF fitting dataset. The mean deviation (MD) is also calculated after the parameterization, 


$$
M D=\frac{\sum_{k}^{n}\left(E_{F F}^{k}-E_{D F T / C C}^{k}\right)}{n}
$$

The RSD and MD can give an overall evaluation of the performance of the fitted FF in reproducing the ab initio data.

A comparison of the interaction energies predicted with $\mathrm{CCFF}$ and the corresponding energies at the DFT/CC level for $\mathrm{CO}_{2}$ and $\mathrm{H}_{2}$ in bulk Si-LTA and nanosheet CHA is shown in Figures S.3 and S.4. For $\mathrm{CO}_{2}$ in $\mathrm{Si}-\mathrm{LTA}$, the DFT/CC calculations of the last iteration span a range of adsorption energies, from -31 to $2 \mathrm{~kJ} / \mathrm{mol}$. The CCFF underestimates the most energetically favorable configurations by about $8 \mathrm{~kJ} / \mathrm{mol}$, and overestimates the least stable configurations by $11 \mathrm{~kJ} / \mathrm{mol}$. This imperfect fit is also observed as high RSD and MD values of 2.8 and $-0.3 \mathrm{~kJ} / \mathrm{mol}$, respectively. A similar trend is seen with $\mathrm{CO}_{2}$ in nanosheet $\mathrm{CHA}$.

For $\mathrm{H}_{2}$ in Si-LTA and OH-CHA-2D, the fitting results are better than those from $\mathrm{CO}_{2}$. The CCFF reproduces the DFT/CC interaction energies for both energetically favorable and unfavorable configurations, with and RSD and MD 0.4 and $0.04 \mathrm{~kJ} / \mathrm{mol}$ for $\mathrm{H}_{2}$ in Si-LTA, and 0.7 and $0.02 \mathrm{~kJ} / \mathrm{mol}$ for $\mathrm{H}_{2}$ in $\mathrm{OH}-\mathrm{CHA}-2 \mathrm{D}$.

In Fang et al.'s previous work, we obtained a better fit for $\mathrm{CO}_{2}$ interactions with Si-CHA where the fitted force field describes both favorable and unfavorable configurations reasonably well. ${ }^{5,23}$ This is probably due to the smaller charges of the Hill-Sauer force field, which has weaker Coulomb interactions that cannot be fully compensated by vdW interactions via force field fitting. 
(a)

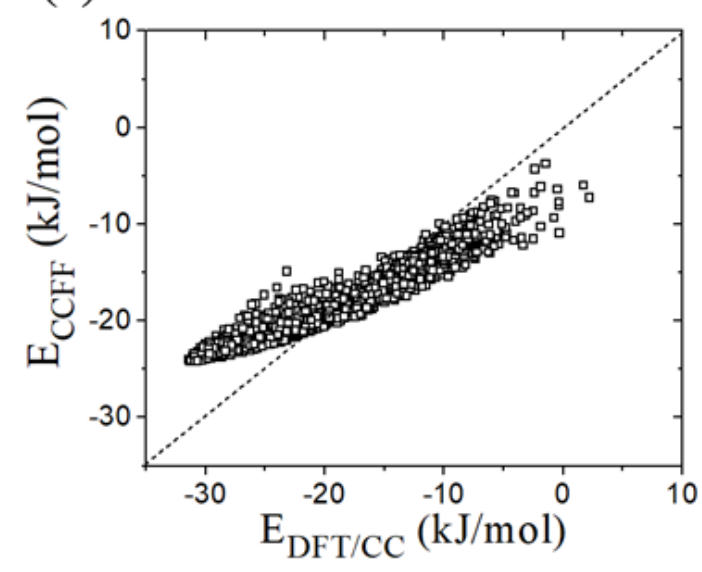

(b)

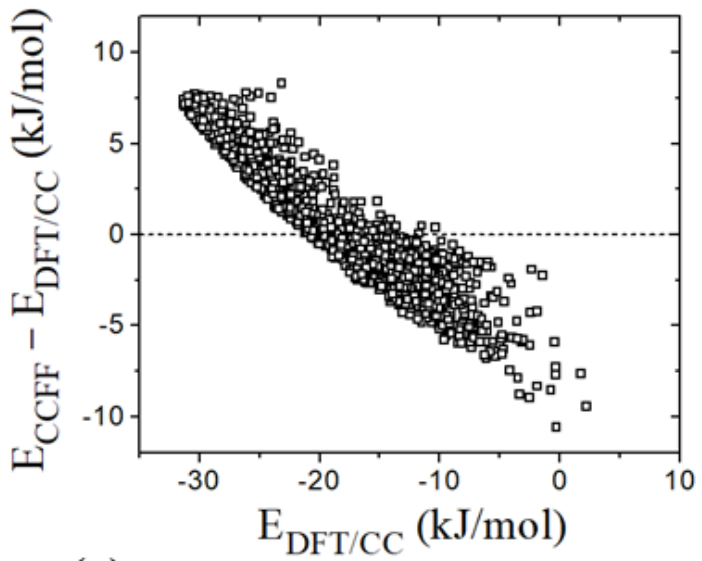

(c)

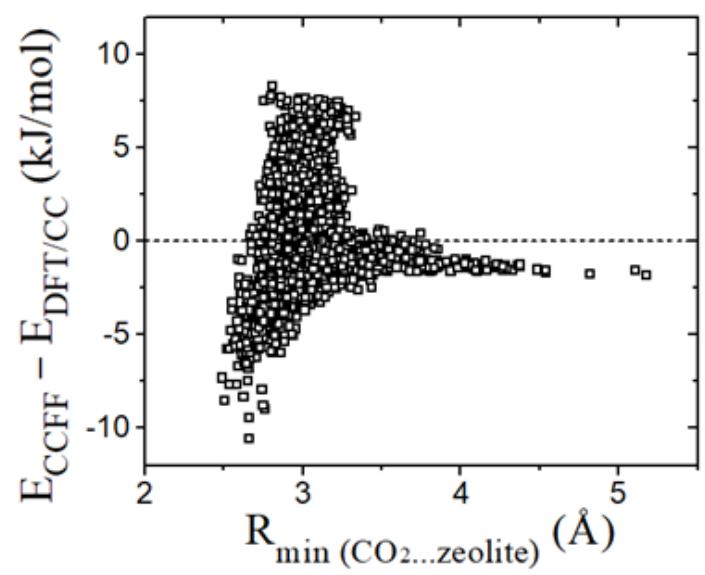

(d)

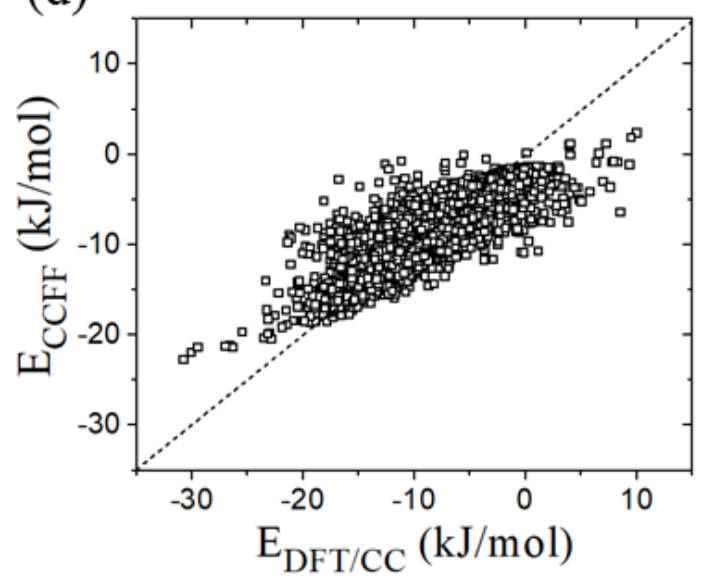

(e)

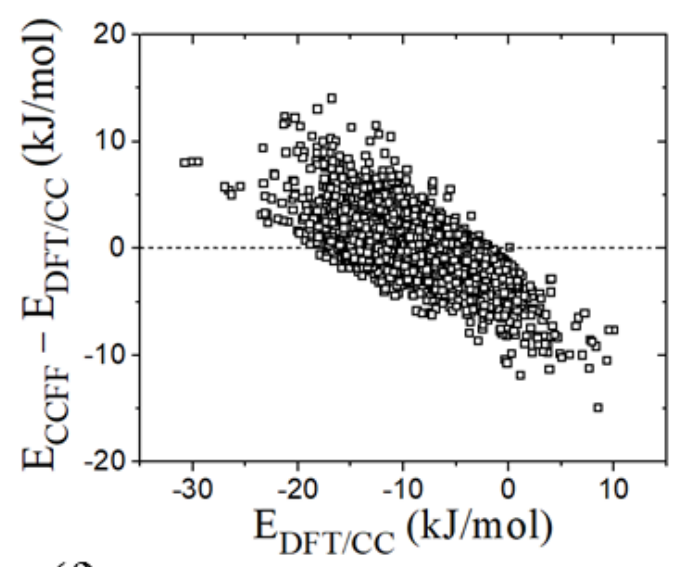

(f)

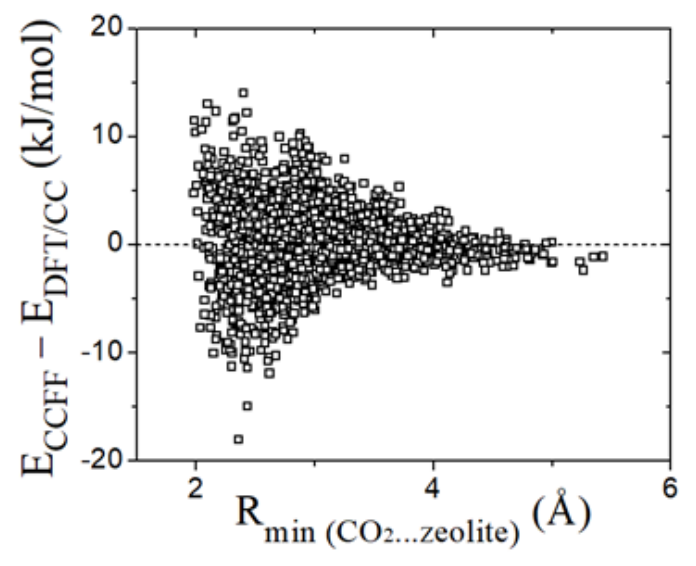

Figure S.3: Force field fitting results for $\mathrm{CO}_{2}$ in $(\mathrm{a}-\mathrm{c}) \mathrm{Si}-\mathrm{LTA}$ and $(\mathrm{d}-\mathrm{f}) \mathrm{OH}-\mathrm{CHA}-$ 2D: (a, d) Comparison of the interaction energies of $\mathrm{CO}_{2}$ in zeolite for CCFF and DFT/CC, $(b, e)$ the difference in interaction energies ( $\left.\mathrm{E}_{\mathrm{CCFF}}-\mathrm{E}_{\mathrm{DFT} / \mathrm{CC}}\right)$ as a function $E_{D F T / C C}$, and (c, f) ECCFF $_{\text {CDFT/CC }}$ as a function of the nearest interatomic distance between the atoms of $\mathrm{CO}_{2}$ and zeolite. A total of $2400 \mathrm{CO}_{2}$ configurations are included for both bulk Si-LTA and nanosheet Si-CHA. 
(a)

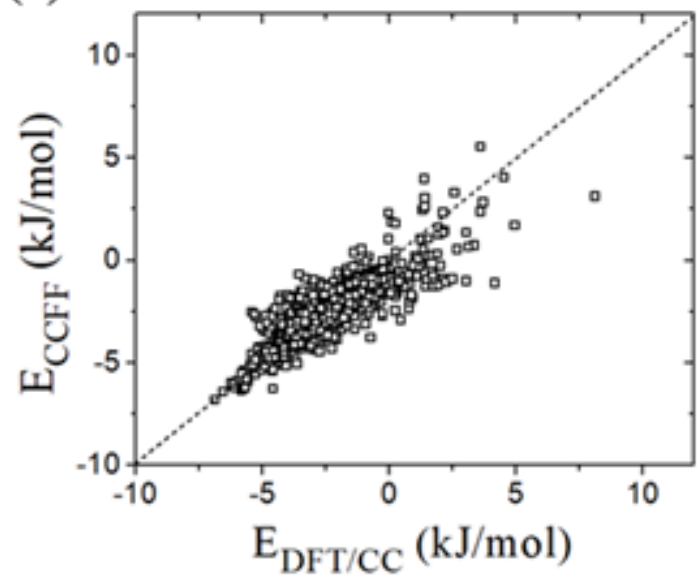

(b)

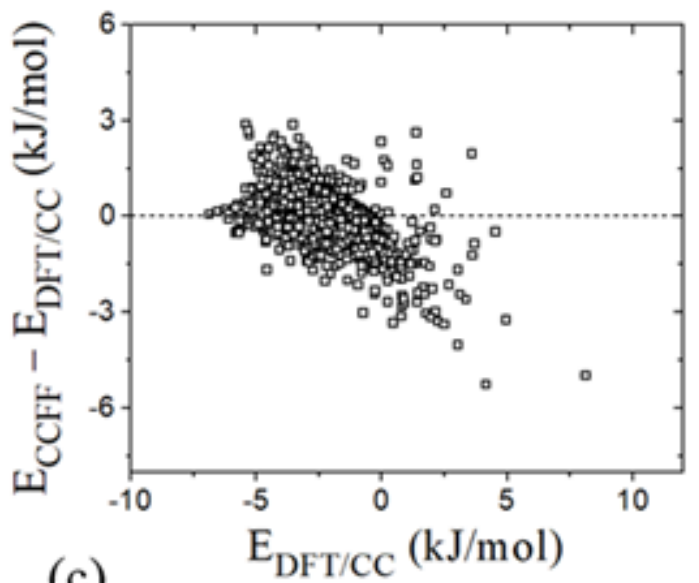

(c)

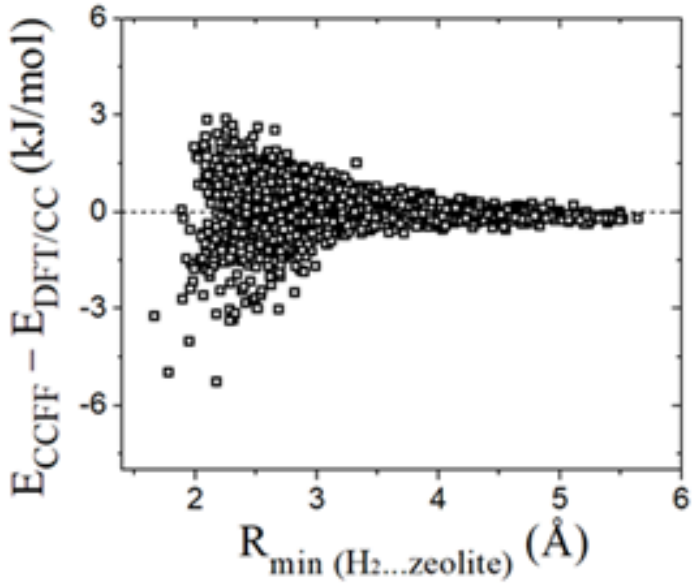

(d)

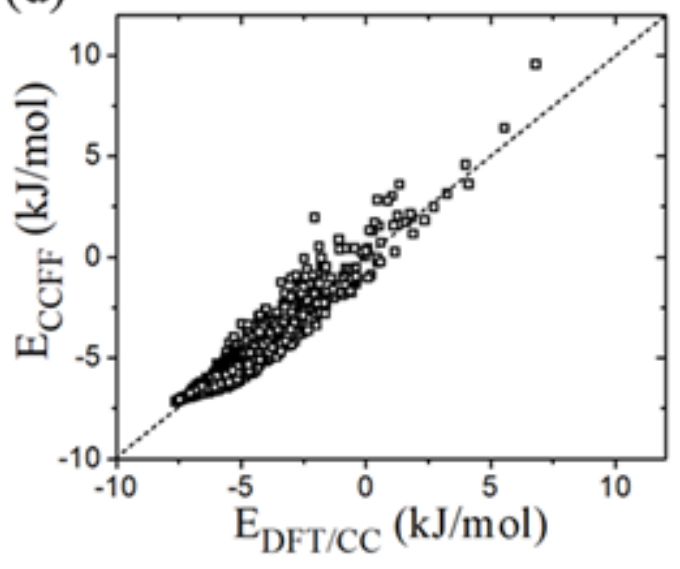

(e)

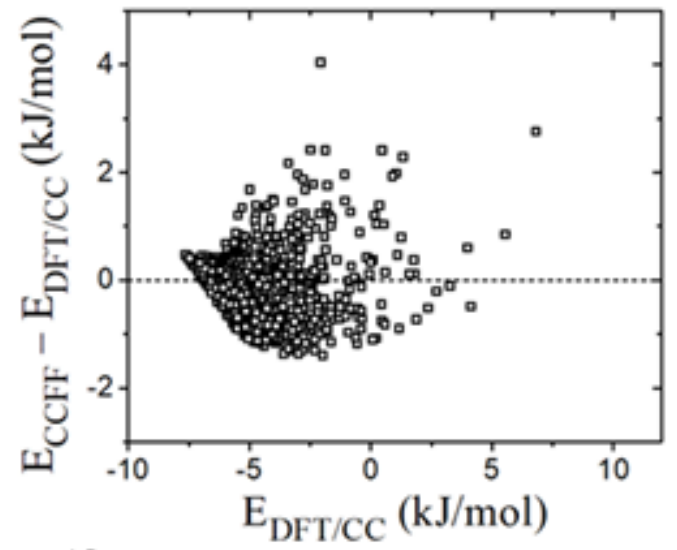

(f)

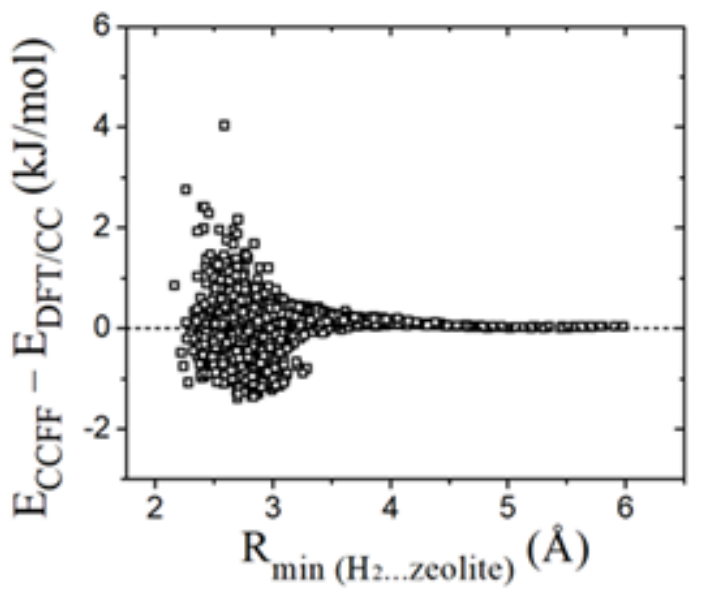

Figure S.4: Force field fitting results for $\mathrm{H}_{2}$ in $(\mathrm{a}-\mathrm{c}) \mathrm{Si}-\mathrm{LTA}$ and (d-f) OH-CHA-2D: (a, d) Comparison of the interaction energies of $\mathrm{H}_{2}$ in zeolite for CCFF and DFT/CC, $(\mathrm{b}, \mathrm{e})$ the difference in interaction energies $\left(\mathrm{E}_{\mathrm{CCFF}}-\mathrm{E}_{\mathrm{DFT} / \mathrm{CC}}\right)$ as a function $\mathrm{E}_{\mathrm{DFT} / \mathrm{CC}}$, and $(c, f) E_{C C F F}-E_{D F T / C C}$ as a function of the nearest interatomic distance between the atoms of $\mathrm{H}_{2}$ and zeolite. A total of $2400 \mathrm{H}_{2}$ configurations are included for both bulk Si-LTA and nanosheet Si-CHA. 


\section{S.2.4 Force Field Validation}

We validated the CCFF listed above by comparing the simulated adsorption isotherms and heats of adsorption for $\mathrm{CO}_{2}$ in siliceous chabazite ( $\mathrm{Si}-\mathrm{CHA}$ ) with available experimental data. The validation results are shown in Figures S.5. CCFF predicts adsorption isotherms well for $\mathrm{CO}_{2}$ in Si-CHA at 301 and $323 \mathrm{~K}$ compared to experimental data from Fang et al. and Pham et al. ${ }^{5,27}$ The heats of adsorption predicted using CCFF agree reasonably well with the calorimetric data from Fang et al. ${ }^{5}$ and the results from Pham et al. that were obtained from the isotherm data using the Clausius-Clapeyron equation. ${ }^{27}$ The deviation is about $2-3 \mathrm{~kJ} / \mathrm{mol}$ at all loadings. We note that it is not possible to validate our FF against equilibrium adsorption data for zeolitic nanosheets because no experimental data of this kind is available.

(a)

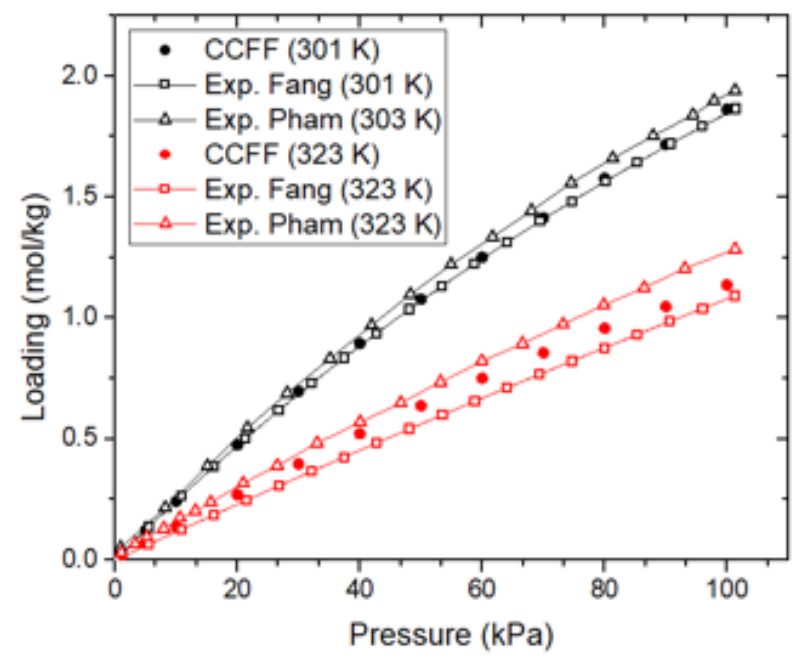

(b)

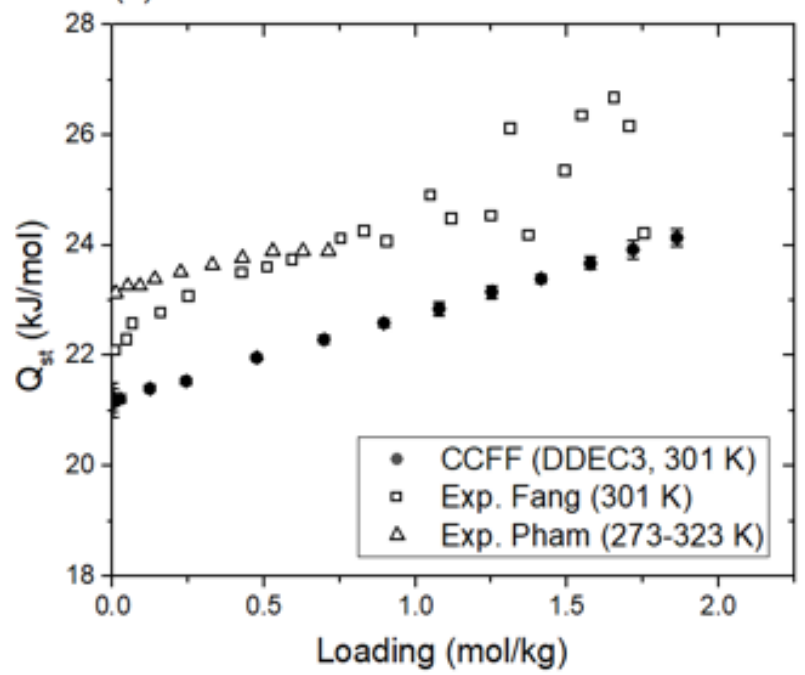

Figure S.5: Comparison of simulated and experimental (a) adsorption isotherms and (b) isosteric heats of adsorption for $\mathrm{CO}_{2}$ in bulk Si-CHA. The experimental data are from Fang et al. and Pham et al. ${ }^{5,27}$ 


\section{S.3 Hydrocarbon Lennard-Jones Parameters}

The hydrocarbon Lennard-Jones parameters for ethane, ethene, propane, and propene obtained from the TraPPE force field, and the zeolite Lennard-Jones parameters obtained from the TraPPE-zeo force field are listed in Table S.3. ${ }^{28-30}$

Table S.3 - Hydrocarbon Lennard-Jones Parameters

\begin{tabular}{|c|c|c|c|c|}
\hline Self Interaction & Reference & $\epsilon / \mathbf{k}_{\mathrm{B}}(\mathbf{K})$ & $\sigma(\AA)$ & Charge (e) \\
\hline $\mathrm{CH}_{3 \_s p 3}$ & 29 & 98.0 & 3.75 & 0 \\
\hline $\mathrm{CH}_{2}$ sp3 & 29 & 46.0 & 3.95 & 0 \\
\hline $\mathrm{CH}_{2 \_ \text {sp2 }}$ & 30 & 85.0 & 3.675 & 0 \\
\hline $\mathrm{CH}_{-}$sp2 & 30 & 47.0 & 3.73 & 0 \\
\hline $\mathrm{Si}$ & 28,31 & 22 & 2.3 & 0.5236 \\
\hline $\mathrm{Oz}\left(\mathrm{O}_{\mathrm{SiOSi}}\right)$ & 28,31 & 53 & 3.3 & -0.2618 \\
\hline $\mathrm{Oz}\left(\mathrm{O}_{\mathrm{SiOH}}\right)$ & 31 & 53 & 3.3 & -0.195 \\
\hline $\mathrm{Hz}$ & 31 & NA & NA & 0.0641 \\
\hline
\end{tabular}

We simulated hydrocarbons as flexible molecules using the parameters given by Granato et al. ${ }^{32}$ The parameters in Table $\mathbf{S . 4}$ refer to the following bond and angle potentials

$$
u_{\text {bond }}=\frac{k_{1}}{2}\left(r-r_{0}\right) \quad u_{\text {angle }}=\frac{k_{2}}{2}\left(\cos \theta-\cos \theta_{0}\right)
$$

where $u_{\text {bond }}$ is the bond energy, $k_{1}$ is an energy scalar, $r$ is the distance between both atoms, $r_{0}$ is the equilibrium bond distance, $u_{\text {angle }}$ is the angle bending energy, $k_{2}$ is an energy scalar, $\theta$ is the angle formed by three atoms, and $\theta_{0}$ is the equilibrium angle. 
Table S.4 - Hydrocarbon Flexibility Parameters ${ }^{32}$

\begin{tabular}{ccccccc}
\hline & \multicolumn{2}{c}{ Single Bond } & \multicolumn{2}{c}{ Double Bond } & \multicolumn{2}{c}{ Angle } \\
& $\left.r_{0}(\AA)\right)$ & $k_{1} / k_{B}\left(\mathrm{~K} / \AA^{2}\right)$ & $r_{0}(\AA)$ & $k_{1} / k_{B}\left(\mathrm{~K} / \AA^{2}\right)$ & $\theta_{0}\left({ }^{\circ}\right)$ & $k_{2} / k_{B}(\mathrm{~K})$ \\
\hline Ethane & 1.54 & 96,500 & $\mathrm{NA}$ & $\mathrm{NA}$ & $\mathrm{NA}$ & $\mathrm{NA}$ \\
Ethene & $\mathrm{NA}$ & $\mathrm{NA}$ & 1.33 & 96,500 & $\mathrm{NA}$ & $\mathrm{NA}$ \\
Propane & 1.54 & 96,500 & $\mathrm{NA}$ & $\mathrm{NA}$ & 114 & 62,500 \\
Propene & 1.54 & 96,500 & 1.33 & 96,500 & 119.7 & 70,400
\end{tabular}

The $\mathrm{CH}_{4}$ self-interaction parameters from the TraPPE force field and the $\mathrm{CH}_{4}$ zeolite interactions from the work of Fang et al. are listed in Table S.5. ${ }^{29,33}$

Table S.5 - $\mathrm{CH}_{4}$ Lennard-Jones Parameters

\begin{tabular}{ccccc}
\hline Self-Interaction & Reference & $\boldsymbol{\epsilon} / \mathbf{k}_{\mathbf{B}}(\mathbf{K})$ & $\boldsymbol{\sigma}(\AA)$ & Charge (e) \\
\hline $\mathrm{CH}_{4}$ & 29 & 147.9 & 3.73 & 0 \\
$\mathbf{C H}_{4}$ Cross Species & & & & \\
\hline $\mathrm{CH}_{4}-\mathrm{Oz}$ & 33 & 109.156 & 3.3815 & \\
$\mathrm{CH}_{4}-\mathrm{Si}$ & 33 & 0 & 0 & \\
$\mathrm{CH}_{4}-\mathrm{Hz}$ & & NA & NA &
\end{tabular}

\section{S.4 Slab Thermalization}

Several NEMD studies have shown that it is critical to model the adsorption and desorption step in simulations of porous nanosheets accurately. Newsome and Sholl showed that a rigid zeolite framework increases surface resistance by repelling attempts at adsorption. ${ }^{34}$ Liu, Nicholson, and Bhatia showed that a temperature gradient develops due to the exothermic/endothermic heats of adsorption/desorption at opposite ends of the nanotube. ${ }^{35}$ As a result of the temperature gradient, their NEMD simulations resulted in slightly higher flux compared to the EMD case. ${ }^{35}$ 
In our simulations, we wanted to allow for local cooling and heating upon desorption and adsorption, so we modeled the edges of our zeolite nanosheets using an NVE thermostat. The interior of the nanosheet was modeled using an NVT thermostat to prevent energy drift. Figure S.6 shows an example of a $14 \mathrm{~nm}$ MFI (010) nanosheet with a $4 \mathrm{~nm}$ NVT thermostat in the interior and a $5 \mathrm{~nm}$ NVE thermostat at each end.

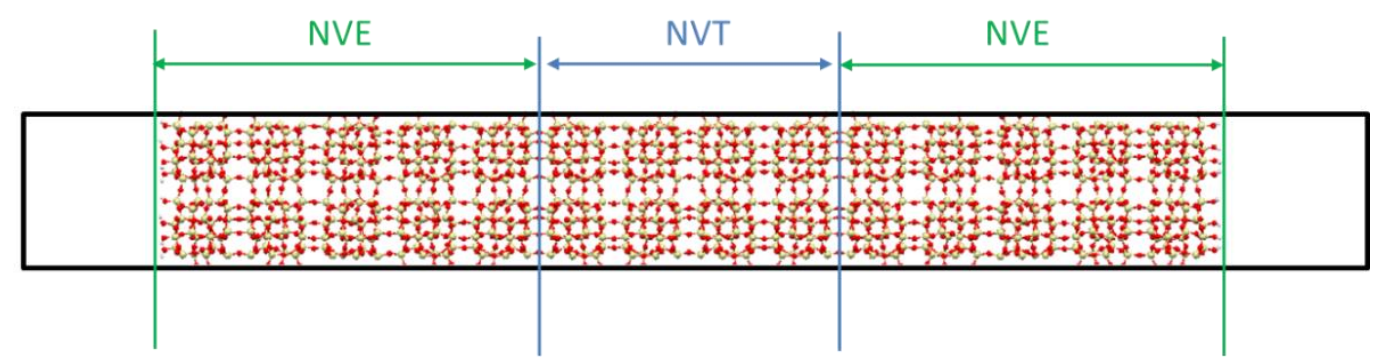

Figure S.6. An MFI (010) $14 \mathrm{~nm}$ slab with a $4 \mathrm{~nm}$ NVT thermostat in the center and an NVE thermostat at each end.

We conducted several simulations to find an appropriate thickness of the NVT region. Ideally the region should be thick enough to maintain constant temperature, but no thicker, lest the thermostat interfere with adsorption and desorption kinetics. For each simulation, any zeolite atom not in the NVT region was included in the NVE regions. We ran EMD simulations of $\mathrm{CO}_{2}$ in a 14 nm MFI (010) slab at 2 bar and $300 \mathrm{~K}$ with a 1 fs time step for $1 \mathrm{~ns}$. Our data was saved every 100 ps and we averaged over 15 independent simulations. To measure desorption, we counted the number of molecules that crossed the cell boundary. We defined a desorption constant equal to

$$
k_{\text {des }}=\frac{j}{A C}
$$

where $j$ is the flux out of the slab, $A$ is the surface area of the slab, and $C$ is the concentration of adsorbate in the slab. ${ }^{36}$ 
Figure S.7(a) shows the effect of the NVT region thickness on $k_{d e s}$, which increases from 0.2 to $0.5 \mathrm{~nm}$, remains roughly constant from 0.5 to $8 \mathrm{~nm}$, and increases thereafter. The initial increase can be explained by Figure S.7(b) which shows that a $0.2 \mathrm{~nm}$ NVT thermostat region is unable to maintain constant temperature. The increase in $k_{d e s}$ from $8 \mathrm{~nm}$ onwards is due to the NVT thermostat's interference with the desorption process, where it likely replenishes the kinetic energy at the surface faster than it would be replenished via heat flux. We found that $0.5 \mathrm{~nm}$ was the thinnest NVT region that maintained a constant temperature, so a $0.5 \mathrm{~nm}$ NVT region was used in all slab simulations. We chose the thinnest region possible to ensure the ability to effectively simulate very thin slabs.

(a)

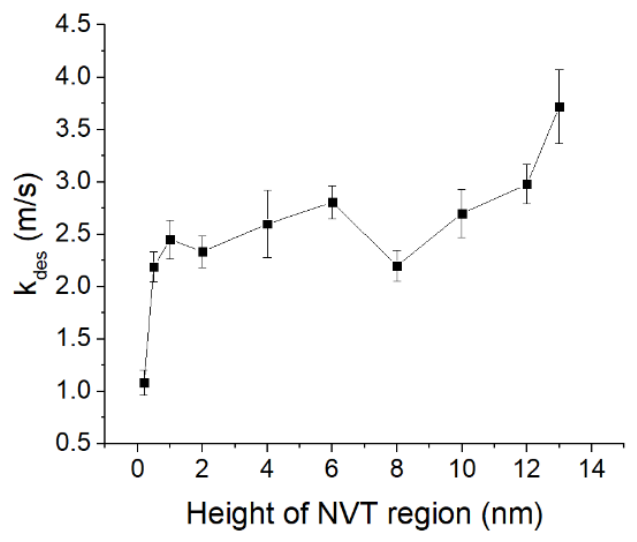

(b)

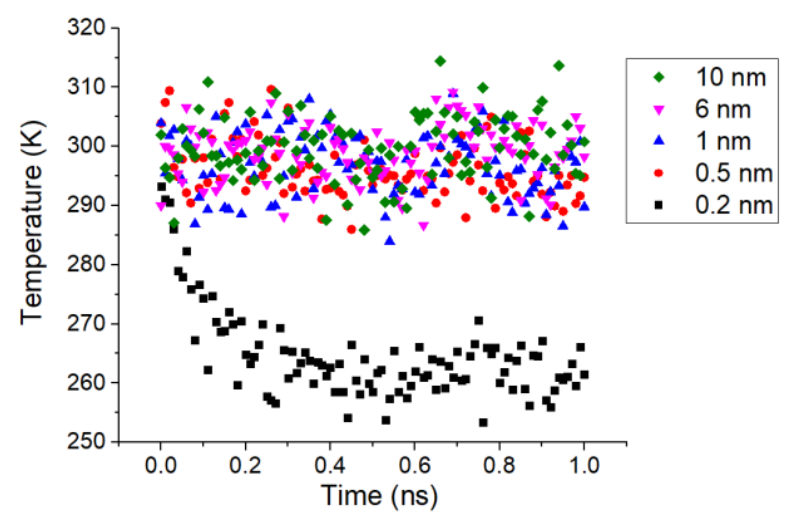

Figure S.7. Simulations of $\mathrm{CO}_{2}$ in a $14 \mathrm{~nm}$ MFI slab at 2 bar and $300 \mathrm{~K}$. (a) $k_{\text {des }}$ increases with the thickness of the NVT region. (b) The system temperature holds steady for NVT regions at least $0.5 \mathrm{~nm}$ thick, but not for the $0.2 \mathrm{~nm}$ region. The legend lists the thickness of each NVT region tested. 


\section{S.5 Convergence}

To calculate accurate diffusivities, it is standard practice to simulate a trajectory that is long enough to capture the characteristic diffusion length, the distance from one transition state to another. In LTA, for example, this is defined as the distance between the centers of two neighboring cages $(1.2 \mathrm{~nm}) .{ }^{33}$ Therefore, an LTA diffusion run that results in mean squared displacement (MSD) larger than $1.44 \mathrm{~nm}^{2}$ implies than on average each molecule has hopped to a neighboring cage and overcome the energy barrier to diffusion at least once.

In slab unit cells, we assume that diffusion is encumbered by resistance inside the zeolite as well as desorption from the surface. Therefore, we defined the characteristic diffusion length as the total length of the unit cell as that would entail movement from the center of one slab to the center of its nearest image. Figure S.8(a) displays an MSD plot averaged over 20 runs of ethene diffusion through a $2 \mathrm{~nm}$ MFI (010) unit cell at $250 \mathrm{~K}$ and 1 molec/uc. Since the squared length of the unit cell is $36 \mathrm{~nm}^{2}$, and the MSD at $50 \mathrm{~ns}$ is $1,648 \mathrm{~nm}^{2}$, each adsorbate on average jumped to a neighboring slab 45 times.

Although we use the MSD to tell if a run was sufficiently long, we use the center of mass squared displacement (CoM SD) to obtain a diffusivity. The CoM SD for the ethene diffusion simulations is shown in Figure S.8(b). The plot is not entirely linear, so a diffusivity derived from the slope will have a high standard deviation. Therefore, we break up the trajectories into nonoverlapping time blocks, calculate the diffusivity using the slope of each block, and measure the standard error in the mean of the set of diffusivity values. ${ }^{37}$ The average diffusivities and errors for the data in Figure S.8 is shown in Table S.6, which shows that the error decreases as the time block size decreases. 

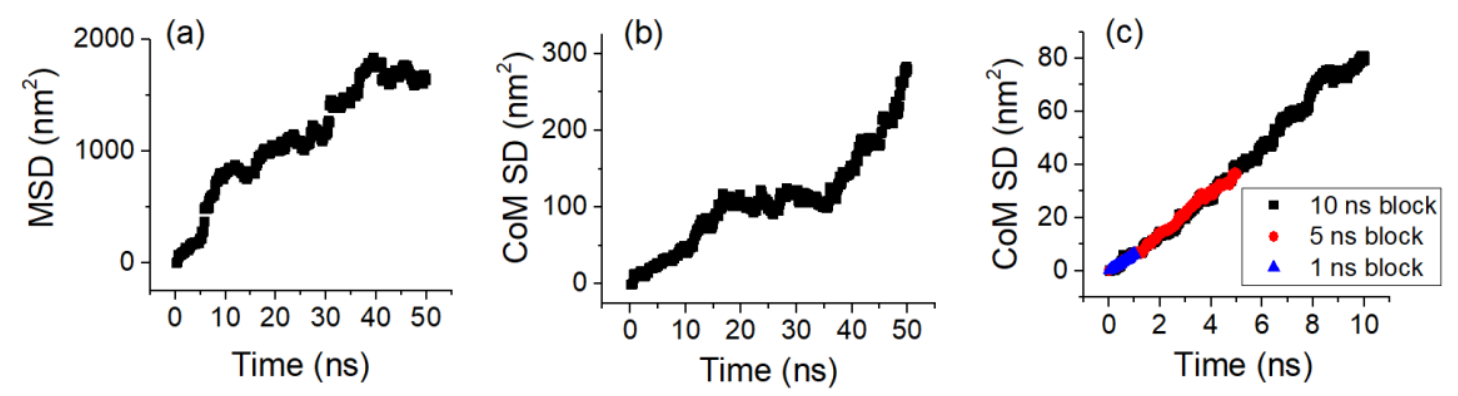

Figure S.8. Trajectories for diffusion of ethene through $2 \mathrm{~nm} \mathrm{MFI}$ at $250 \mathrm{~K}$ and 1 molec/uc displaying (a) the MSD of the total run, (b) the CoM SD for the total run, and (c) the CoM SD for time blocks of different size.

Table S.6 - Diffusivity and Standard Error of Mean for Ethene in a 2nm MFI Slab

\begin{tabular}{ccccc}
\hline Time block (ns) & $\mathbf{5 0}$ & $\mathbf{1 0}$ & $\mathbf{5}$ & $\mathbf{1}$ \\
\hline $\mathrm{D}_{\text {z,zeo }}\left(\mathrm{m}^{2} / \mathrm{s} \mathrm{E}-10\right)$ & 2.5 & 3.9 & 3.7 & 3.7 \\
$\mathrm{Sm}\left(\mathrm{m}^{2} / \mathrm{s} \mathrm{E}-10\right)$ & 1.8 & 1.1 & 0.9 & 0.7
\end{tabular}

In order to use the diffusivity from the $1 \mathrm{~ns}$ time block, it is best to ensure that it is statistically equivalent to output from larger time blocks. Table S.6 shows that the diffusivity of the 1 ns time block is within the margin of error of the larger time blocks. ${ }^{37}$ In addition, Figure S.8(c) shows that the slopes for various time blocks are overlapping. This data allows us to conclude that the $1 \mathrm{~ns}$ time block is sampling the same phenomena as larger time blocks.

There are some scenarios in which the diffusion mechanism observed at $1 \mathrm{~ns}$ is different than that observed at larger time intervals. Figure S.9 shows trajectories for propane diffusion through a $10 \mathrm{~nm}$ MFI (010) slab at $250 \mathrm{~K}$ and 1 molec/uc. The CoM SD of different time blocks in Figure S.9(c) do not share the same slope. In this instance the $1 \mathrm{~ns}$ time block is capturing only diffusion through the slab, whereas the $5 \mathrm{~ns}$ and $10 \mathrm{~ns}$ time blocks capture both diffusion through the slab and desorption onto a neighboring slab. In such scenarios, we used the long time slope from the full 50 ns trajectory. 

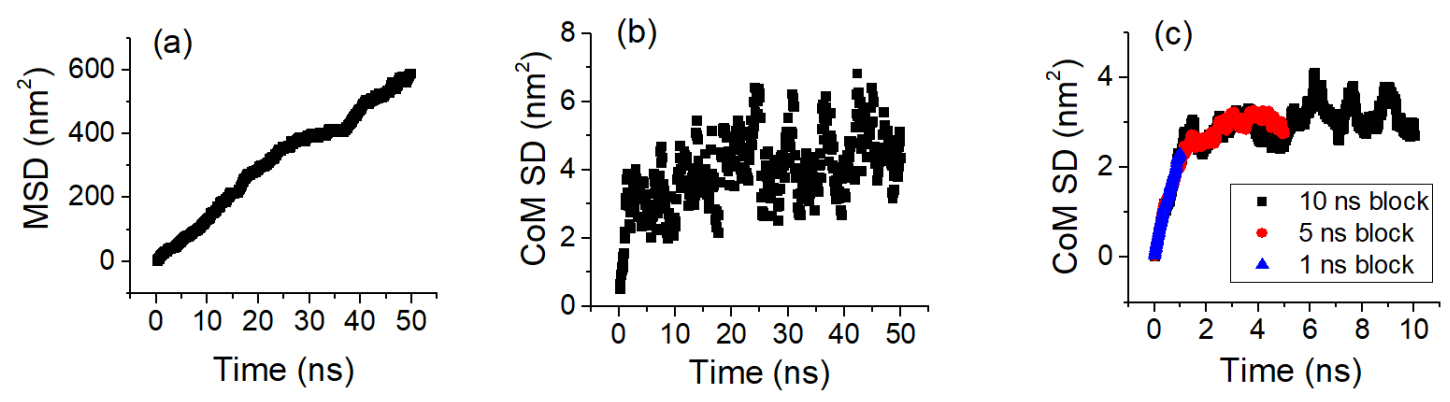

Figure S.9. Trajectories for diffusion of propane through $10 \mathrm{~nm}$ MFI at $250 \mathrm{~K}$ and 1 molec/uc displaying (a) the MSD of the total run, (b) the CoM SD for the total run, and (c) the CoM SD for time blocks of different size.

\section{S.6 Defining the Zeolite/Gas Interface}

In the main text of this manuscript, we describe using equation 4 to calculate an effective corrected diffusivity $\left(\mathrm{D}_{\mathrm{z}, \mathrm{zeo}}\right)$ across the zeolite nanosheet. Here, we describe how we define the boundary between the nanosheet and the gas layer. The adsorption profile for $\mathrm{CO}_{2}$ in $\mathrm{MFI}$ at high loading in Figure S.10(a) shows that molecules form adsorption layers at both ends of the nanosheet. This external layering does not occur in all cases, as seen in the case of propane at low temperature and low loading in Figure S.10(b).
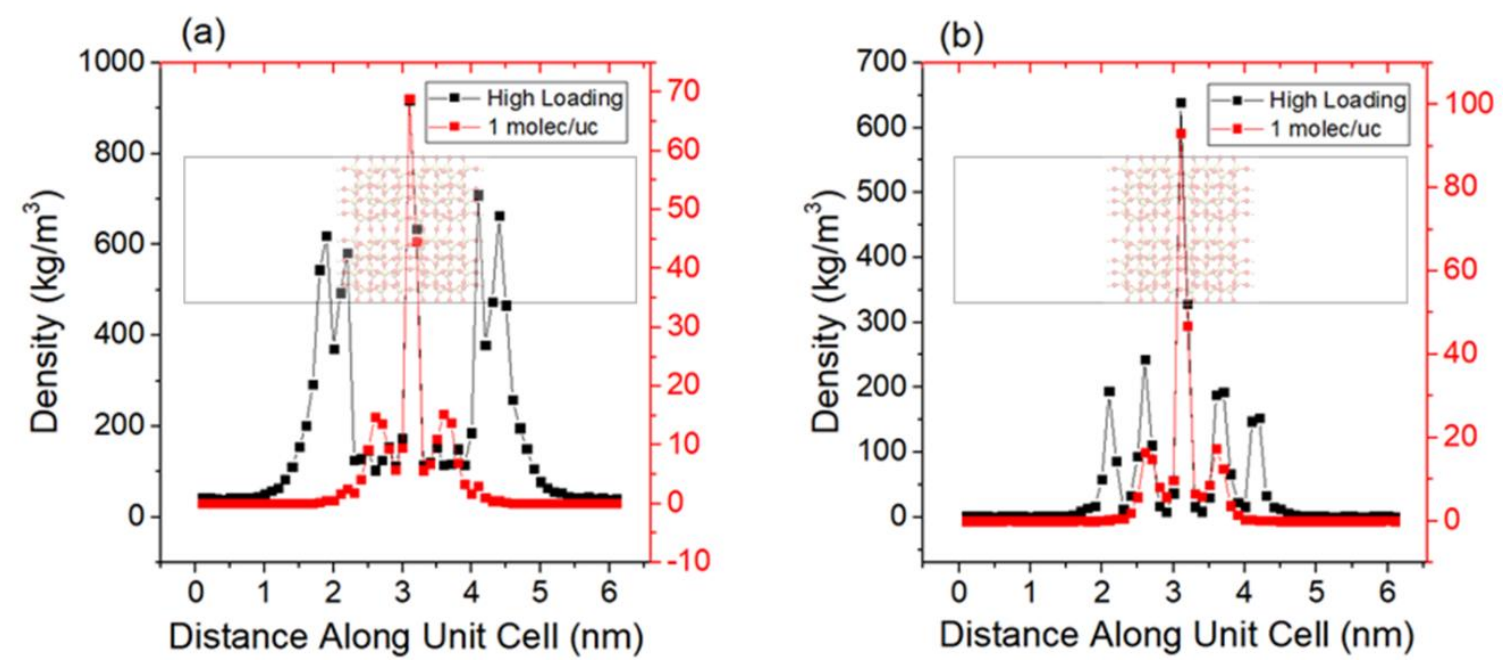

Figure S.10. Density profiles in a $2.2 \mathrm{~nm}$ MFI (010) slab at $250 \mathrm{~K}$ for (a) $\mathrm{CO}_{2}$ and (b) propane. The unit cell is superimposed near the center of each graph. 
To test whether the $\mathrm{D}_{z, \text { zeo }}$ should be measured across a region that includes these adsorption layers, we calculated $\mathrm{D}_{\text {z,zeo }}$ for $\mathrm{CO}_{2}$ diffusion through a $2 \mathrm{~nm}$ MFI (010) unit cell using four different adsorption layer correction $\left(L_{c o r}\right)$ estimates. This correction was applied (shown in red) to equation 4 of the main text such that

$$
D_{z, z e o}=\frac{N_{s y s}^{2}}{2 N_{z e o+\operatorname{cor}}\left(\frac{L_{g a s}-L_{\text {cor }}}{L_{z e o}+L_{L c o r}}+1\right)} \lim _{t \rightarrow \infty} \frac{1}{t}\left\langle\left|\Delta z_{\text {sys,com }}\right|^{2}\right\rangle
$$

$N_{z e o+c o r}$ is the sum of the molecules of gas in the zeolite proper (silanol $\mathrm{H}$ on one end to silanol $\mathrm{H}$ on the opposite end) and the molecules inside the adsorption layers of length $L_{c o r}$ at each end.

Dutta and Bhatia tested two different values of $L_{c o r}(0 \mathrm{~nm}$ and total gas phase length) to distinguish internal and external resistance. ${ }^{38}$ The equations they used to calculate diffusivity tracked a molecule's trajectory through a predetermined section of the nanosheet unit cell, as determined by $L_{c o r} \cdot{ }^{38}$ If the section ended at the surface of the zeolite, the resistance the molecule encountered was due to the zeolite media and desorption. If the section encompassed the entire unit cell, then the molecule also encountered resistance from adsorption and gas phase movement. ${ }^{38}$ Since our method to calculate surface resistance is functionally equivalent to theirs, ${ }^{35}$, ${ }^{38}$ we used different values of $L_{c o r}$ to quantify the magnitude of different resistances.

Our objective was to calculate the surface resistance due to adsorption and desorption. Since these events take place within the adsorption layers, the most accurate $L_{c o r}$ is one which captures the length of the adsorption layer(s) but no more. Figure S.11 shows the surface resistances obtained for $\mathrm{CO}_{2}$ diffusion through a $2 \mathrm{~nm}$ MFI unit cell using various $L_{c o r}$. The “Tailored Manually" $L_{c o r}$ was obtained by visually estimating the size of the adsorption layer from adsorption profiles for each temperature and pressure condition and are listed in Table S.7. We 
view this result as the correct value of $L_{c o r}$, but it is impractical to estimate the value by hand for each simulation. Our aim below, therefore, is to establish an algorithmic approach to this issue.

(a)

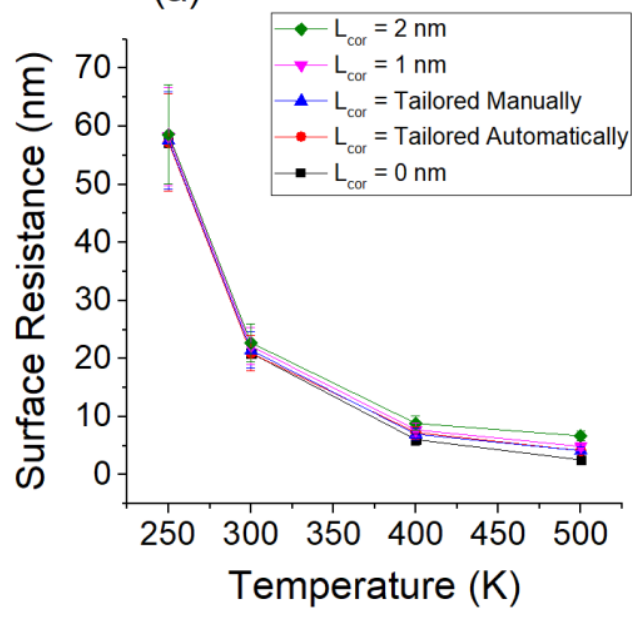

(b)

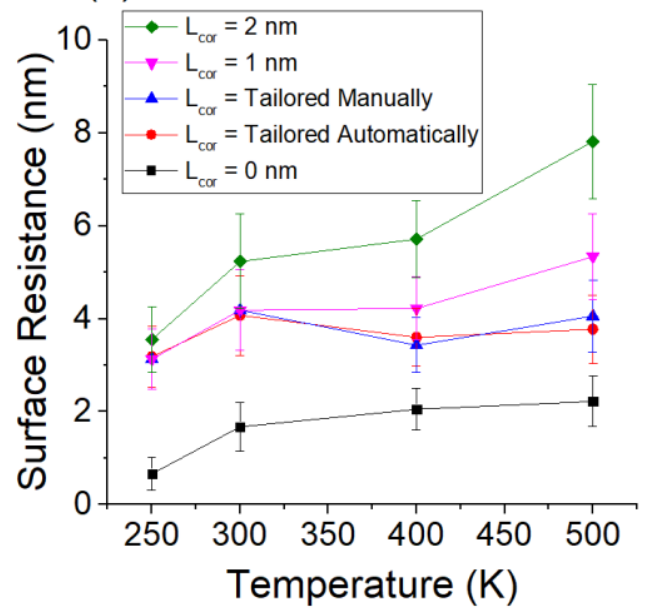

Figure S.11. A comparison of $\mathrm{CO}_{2}$ surface resistance calculated using $\mathrm{D}_{0, \mathrm{eff}}$ measured across the length of the zeolite (without correction) or length of the zeolite and the adsorption layer (with correction) simulated at a loading of (a) 1 molec/uc and (b) high loading.

Table S.7 - Tailored $L_{c o r}$ for $\mathrm{CO}_{2}$ in a 2 nm MFI Slab

\begin{tabular}{ccccc}
\hline Temperature & $250 \mathrm{~K}$ & $300 \mathrm{~K}$ & $400 \mathrm{~K}$ & $500 \mathrm{~K}$ \\
\hline 1 molec/uc $L_{\text {cor }}(\mathrm{nm})$ & 0.1 & 0.2 & 0.4 & 0.6 \\
High Loading $L_{\text {cor }}(\mathrm{nm})$ & 1 & 1 & 0.5 & 0.5
\end{tabular}

Since the largest adsorption layers were $\sim 1 \mathrm{~nm}$ in length, we first employed an $L_{c o r}$ of length $1 \mathrm{~nm}$. We also tested $L_{\text {cor }}$ with lengths $0 \mathrm{~nm}$ and $2 \mathrm{~nm}$. Figure $\mathbf{S . 1 1}$ shows that the $L_{\text {cor }}$ value does not have a great effect on surface resistance when temperature and pressure are low, but it does have a greater effect when temperature and pressure are high. At high temperature and pressure, molecules spend a larger portion of time outside the nanosheet than they do at lower temperature and pressure, so larger $L_{\text {cor }}$ measure larger gas phase resistances. Dutta and Bhatia found that gas phase resistance (adsorption and gas movement) only amounted to a maximum of 
$25 \%$ of total resistance. ${ }^{38} \mathrm{We}$ examined a wider range of conditions and found that adsorption and gas phase resistance can account for up to $70 \%$ of the total surface resistance.

Motivated by the results above we developed a simple algorithm to automatically

determine $L_{c o r}$. With this approach $L_{c o r}$ is defined to be the largest distance from the nanosheet surface at which the average density of the adsorbate is $10 \%$ larger than the average gas phase density. Comparisons between the automatically tailored approach and the manually tailored approach in Figure S.11 show similar results, so we used this algorithm in all calculations reported in the manuscript.

\section{S.7 Adsorbate Density in Nanosheets}

Figure S.12 shows the propane density in an MFI (010) slab and an MFI (010) bulk structure. The average density in the bulk is $152 \mathrm{~kg} / \mathrm{m}^{3}$ while the average density in the slab is 118 $\mathrm{kg} / \mathrm{m}^{3}$, so the slab has $77 \%$ of the bulk density. The density profile in the bulk shows a repeat pattern of a large peak followed by two smaller peaks, with the large peaks occurring at the center of the MFI a and $b$ channel intersections. The center of the MFI slab has such a channel intersection with an accompanying large peak. Though the surface on each side has half the volume of the full intersection, it has less than half of the full intersection density. 

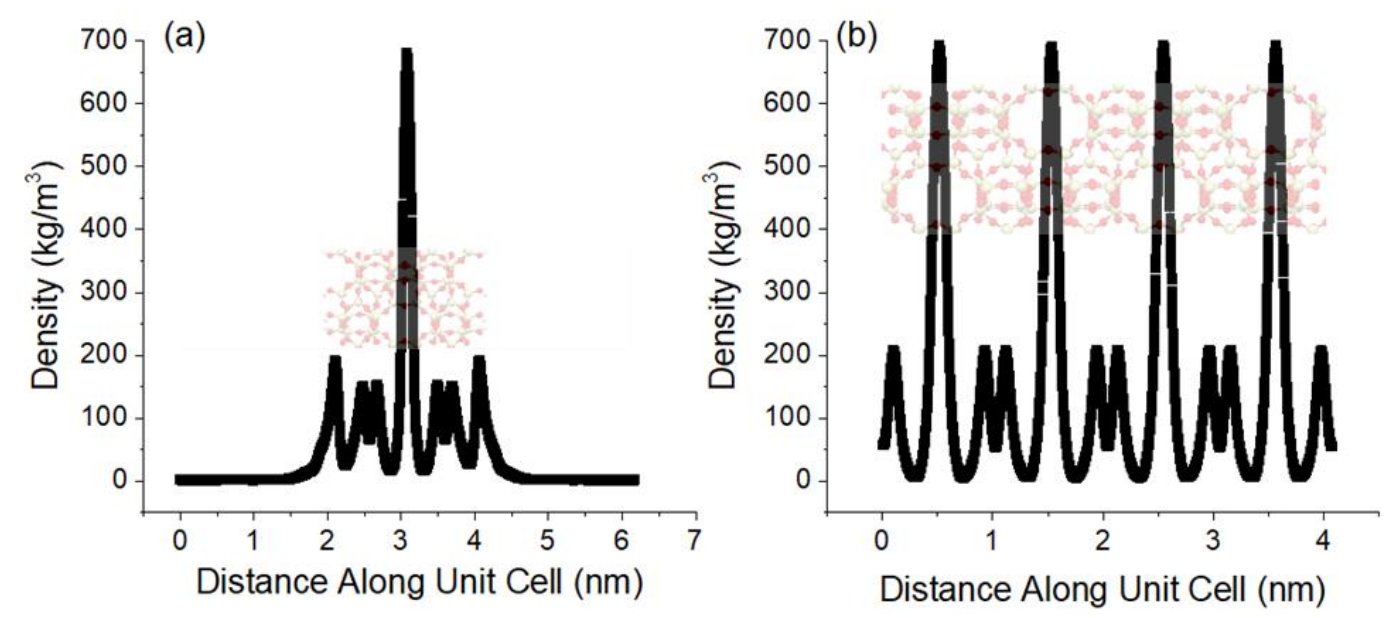

Figure S.12. The density profile of propane post equilibration at 0.5 bar and $250 \mathrm{~K}$ in an MFI (010) (a) $2 \mathrm{~nm}$ slab and (b) $4 \mathrm{~nm}$ bulk unit cell.

Figure S.13 shows the $\mathrm{CO}_{2}$ density in an MFI (010) slab and an MFI (010) bulk structure.

The average density in the bulk is $277 \mathrm{~kg} / \mathrm{m}^{3}$ while the average density in the slab is $269 \mathrm{~kg} / \mathrm{m}^{3}$, so the slab has $97 \%$ of the bulk density.
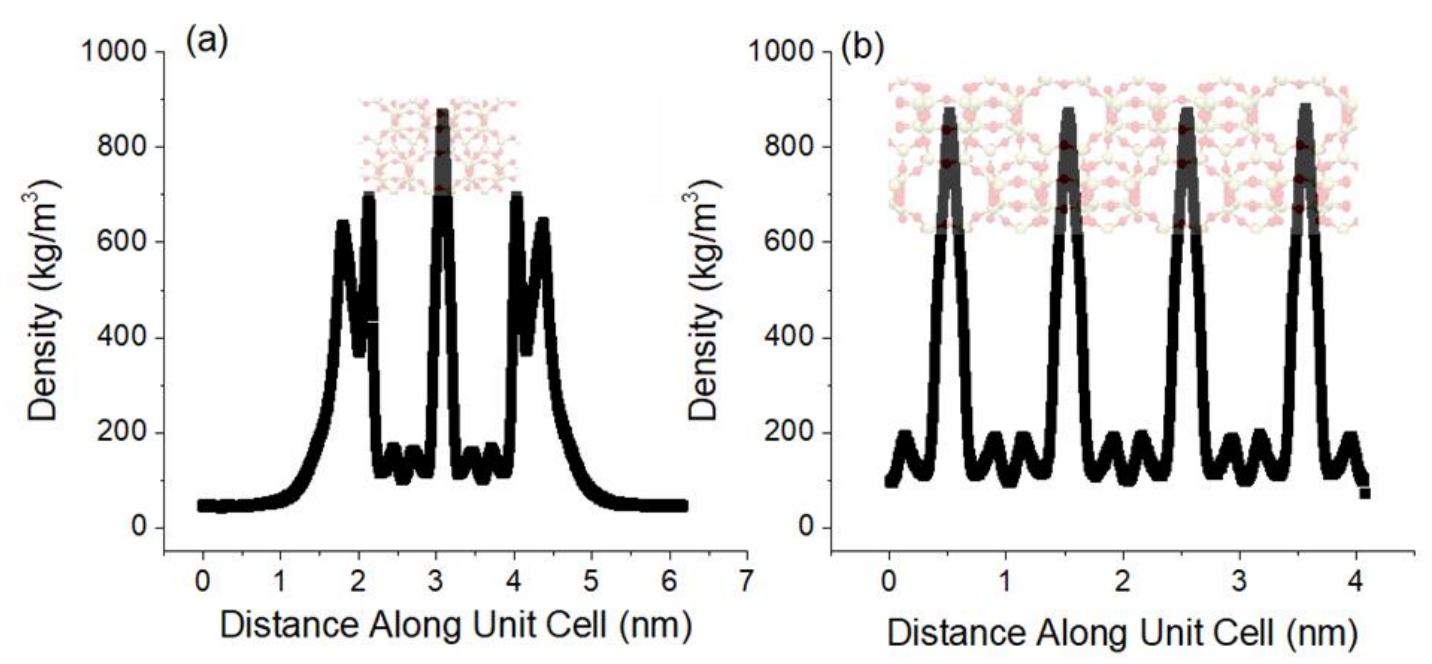

Figure S.13. The density profile of $\mathrm{CO}_{2}$ post equilibration at 15 bar and 250 $\mathrm{K}$ in an MFI (010) (a) $2 \mathrm{~nm}$ slab and (b) $4 \mathrm{~nm}$ bulk unit cell.

\section{S.8 Activation Energy}

Figure S.14 shows an Arrhenius plot used to find the effective activation energies associated with the surface resistance in an MFI (010) nanosheet for the seven molecules we 
studied. For this analysis we set $\mathrm{R}_{\text {surf }}$ equal to the surface resistance as defined in equation 6 rather than the surface resistance equivalent height as defined in equation 10 (and used in throughout the manuscript) to avoid including information from $\mathrm{D}_{0 \text {,bulk }}$ included in the latter term. Although some curvature can be seen in the data for propane and propene, the effective activation energies were obtained simply by linear fits to each data set in Figure S.14(a).
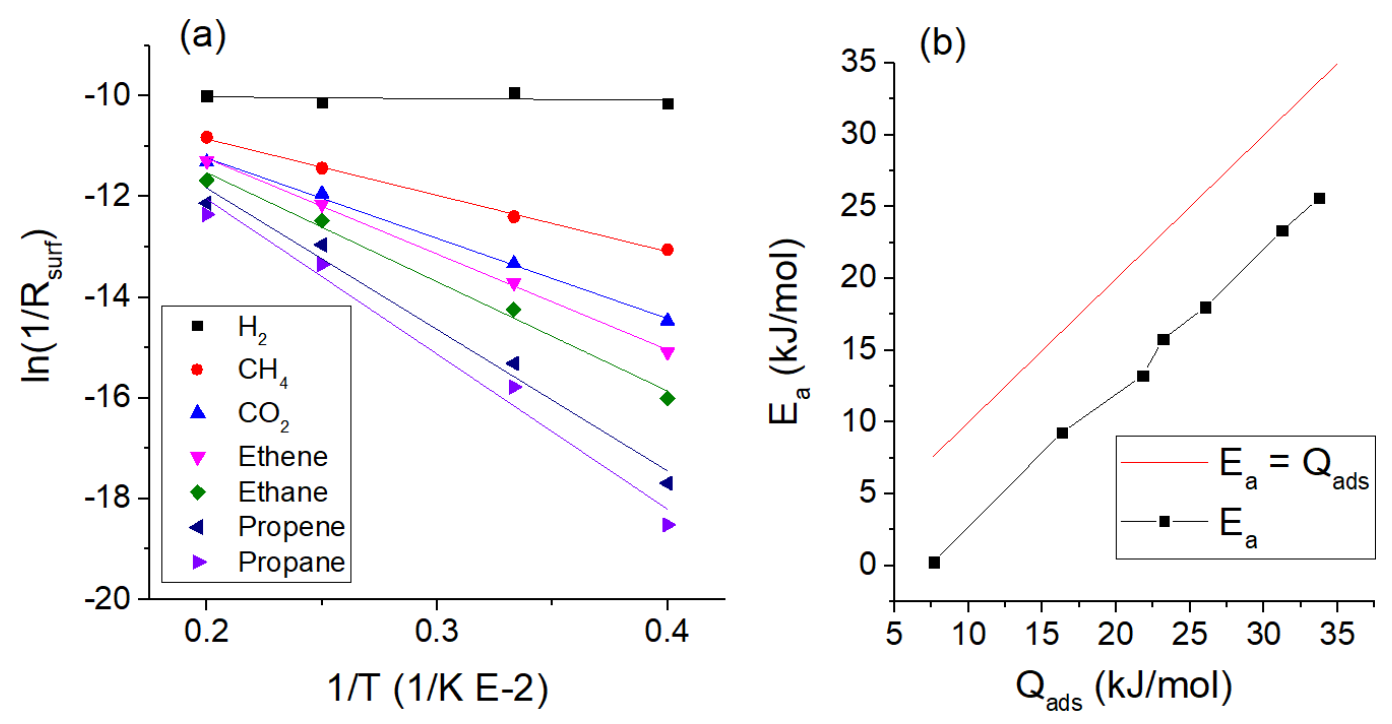

Figure S.14. (a) Arrhenius plots and lines of best fit based on the surface resistance in $2 \mathrm{~nm}$ MFI (010) slabs at a loading of 1 molec/uc. (b) The $\mathrm{Ea}_{\mathrm{a}}$ graphed against the Qads for all seven molecules.

\section{S.9 High Loading}

The MFI surface resistances displayed in Figure 2 of the main text were calculated at a high and low loading scenario. For low loading, we used one molecule in the slab unit cell, and two molecules in the MFI $1 \times 2 \times 1$ supercell. For high loading, we used the loadings shown in Table S.8. Some of the loadings in the bulk unit cell portion of the table have a $1 / 2$ molecule because the GCMC simulation sometimes populates the $1 \times 2 \times 1$ supercell with an odd number of molecules but the numbers in Table S.8 were divided in half to correspond to one unit cell. The slab is equivalent to one unit cell of MFI so the simulation loadings are reported as is. 
Table S.8 - High Loading at each Temperature

\begin{tabular}{|c|c|c|c|c|c|c|c|}
\hline \multirow[b]{2}{*}{ Temperature (K) } & \multicolumn{7}{|c|}{$\begin{array}{c}\text { Slab MFI (010) } \\
\text { Loading (molec/uc) }\end{array}$} \\
\hline & $\mathrm{H}_{2}$ & $\mathrm{CH}_{4}$ & $\mathrm{CO}_{2}$ & ethane & ethene & propane & propene \\
\hline 250 & 28 & 31 & 47 & 19 & 18 & 11 & 11 \\
\hline 300 & 22 & 22 & 36 & 25 & 23 & 12 & 12 \\
\hline 400 & 15 & 12 & 18 & 17 & 17 & 21 & 20 \\
\hline \multirow[t]{2}{*}{500} & 12 & 8 & 11 & 11 & 10 & 12 & 12 \\
\hline & \multicolumn{7}{|c|}{ Bulk MFI (010) loading (molec/uc) } \\
\hline 250 & 10 & 16.5 & 22 & 16 & 16 & 12 & 12 \\
\hline 300 & 6.5 & 13 & 19 & 15 & 15 & 11.5 & 11.5 \\
\hline 400 & 3.5 & 6.5 & 12 & 11 & 10.5 & 10.5 & 10.5 \\
\hline 500 & 2 & 3 & 6 & 5.5 & 6 & 7 & 7.5 \\
\hline
\end{tabular}

To determine the saturation loadings, we developed the isotherms shown in Figures S.15, S.16, and S.17.
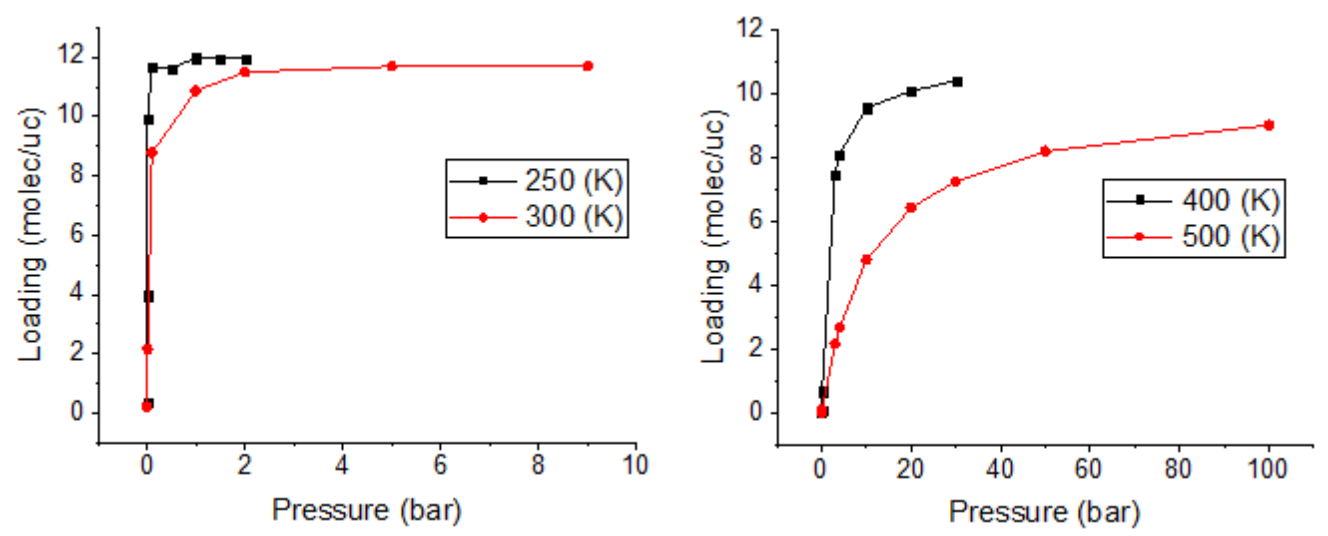

Figure S.15. Propane isotherms in bulk MFI.
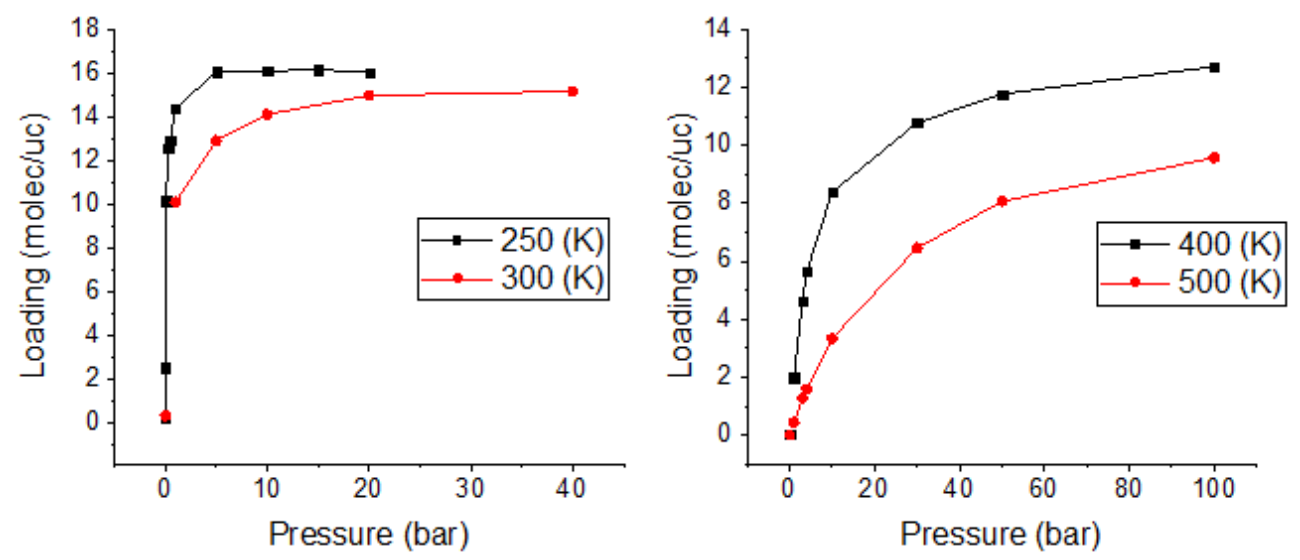

Figure S.16. Ethane isotherms in bulk MFI. 

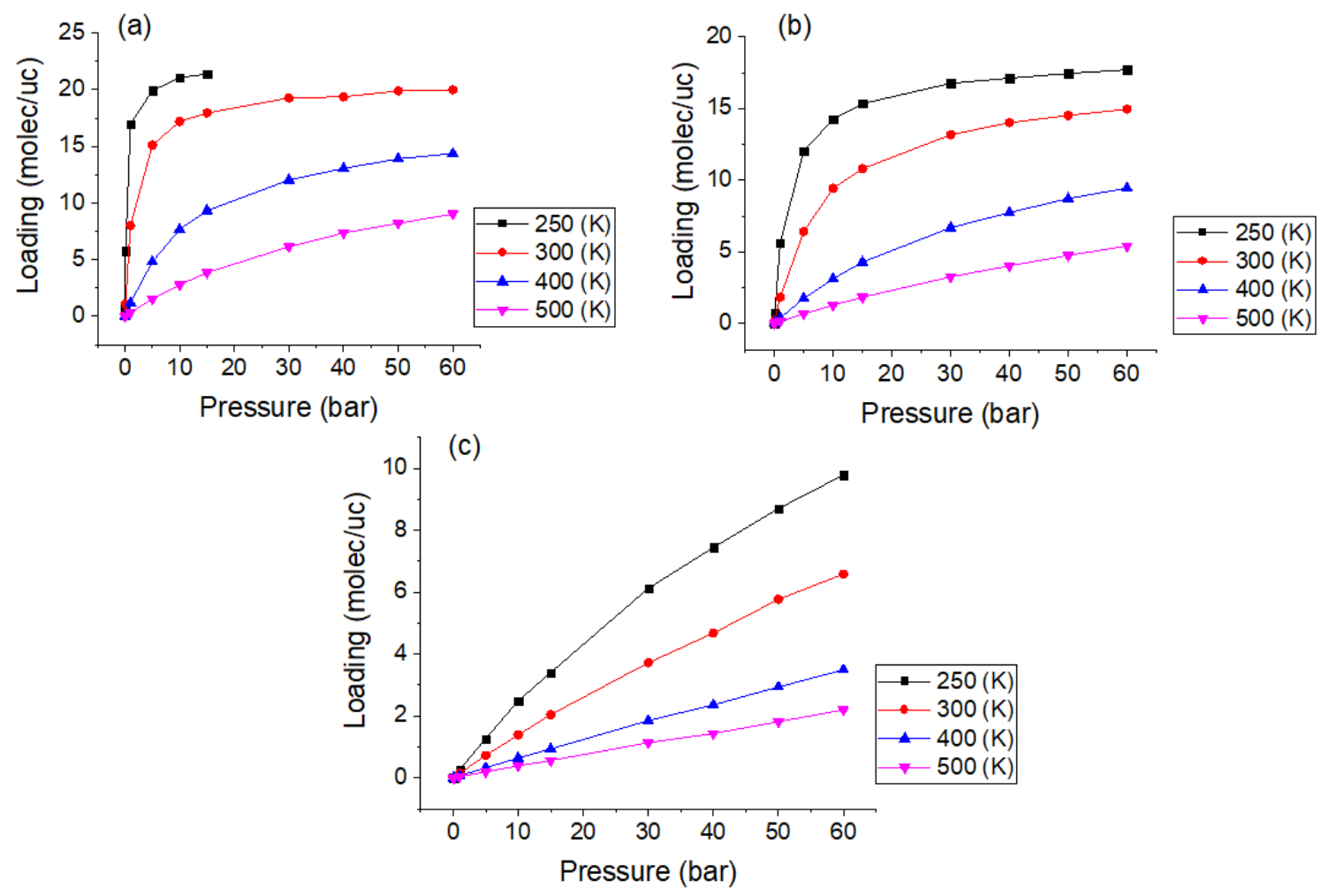

Figure S.17. (a) $\mathrm{CO}_{2}$, (b) $\mathrm{CH}_{4}$, and (c) $\mathrm{H}_{2}$ isotherms in bulk MFI.

We determined the saturation pressure by visually observing were the curve became horizontal. The saturation pressures are shown in Table S.9. Though they were taken from the bulk isotherm, we used the same pressure to load both the bulk and slab unit cells. For species whose isotherm does not follow the standard shape, such as $\mathrm{H}_{2}$, we simply chose a high pressure from within the examined pressure range. Additionally, the saturation pressure from the ethane isotherm was used for ethene and the saturation pressure from the propane isotherm was used for propene. 
Table S.9 - Saturation Pressures

\begin{tabular}{cccccccc}
\hline & \multicolumn{7}{c}{ Pressure (bar) } \\
Temperature $(\mathrm{K})$ & $\mathrm{H}_{2}$ & $\mathrm{CH}_{4}$ & $\mathrm{CO}_{2}$ & ethane & ethene & propane & propene \\
\hline 250 & 60 & 30 & 15 & 1 & 1 & 0.5 & 0.5 \\
300 & 60 & 30 & 30 & 20 & 20 & 3 & 3 \\
400 & 60 & 30 & 30 & 30 & 30 & 30 & 30 \\
500 & 60 & 30 & 30 & 30 & 30 & 30 & 30
\end{tabular}

\section{S.10 All Ideal Selectivities}

The ideal selectivities for $\mathrm{H}_{2} / \mathrm{CO}_{2}, \mathrm{CH}_{4} / \mathrm{CO}_{2}$, ethene/ethane, and propene/propane for MFI are shown in Figure S.18. For each case, the slab ideal selectivity is higher that the bulk ideal selectivity due to surface resistance having a larger effect on the molecule with the larger heat of adsorption.

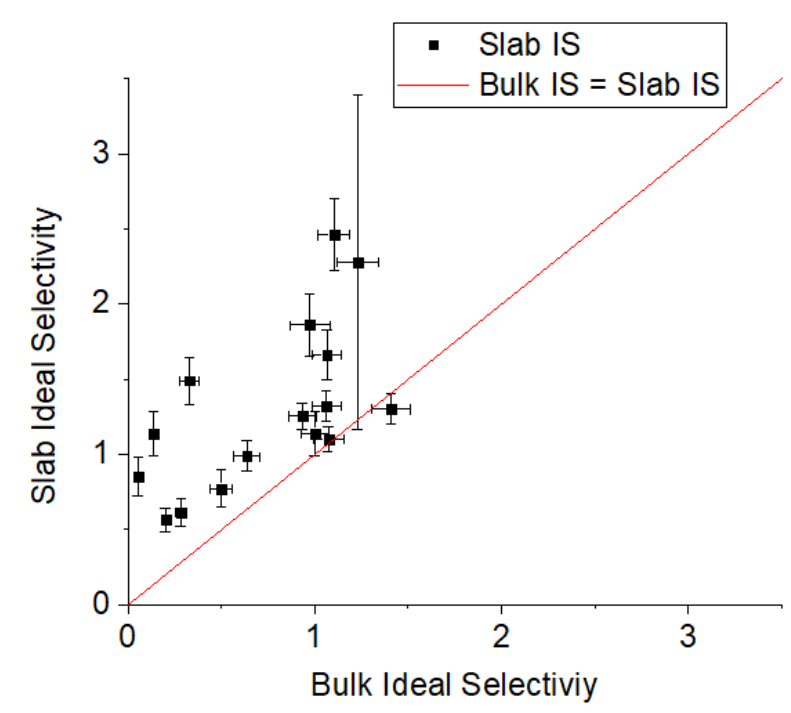

Figure S.18. The slab ideal selectivity and bulk ideal selectivity for $\mathrm{H}_{2} / \mathrm{CO}_{2}, \mathrm{CH}_{4} / \mathrm{CO}_{2}$, ethene/ethane, and propene/propane in bulk MFI and a $2 \mathrm{~nm}$ MFI (010) slab at 1 molec/uc and 250, 300, 400, and $500 \mathrm{~K}$. 


\section{S.11 $D_{\text {slab,LNR }}$ Prediction for Six Frameworks}
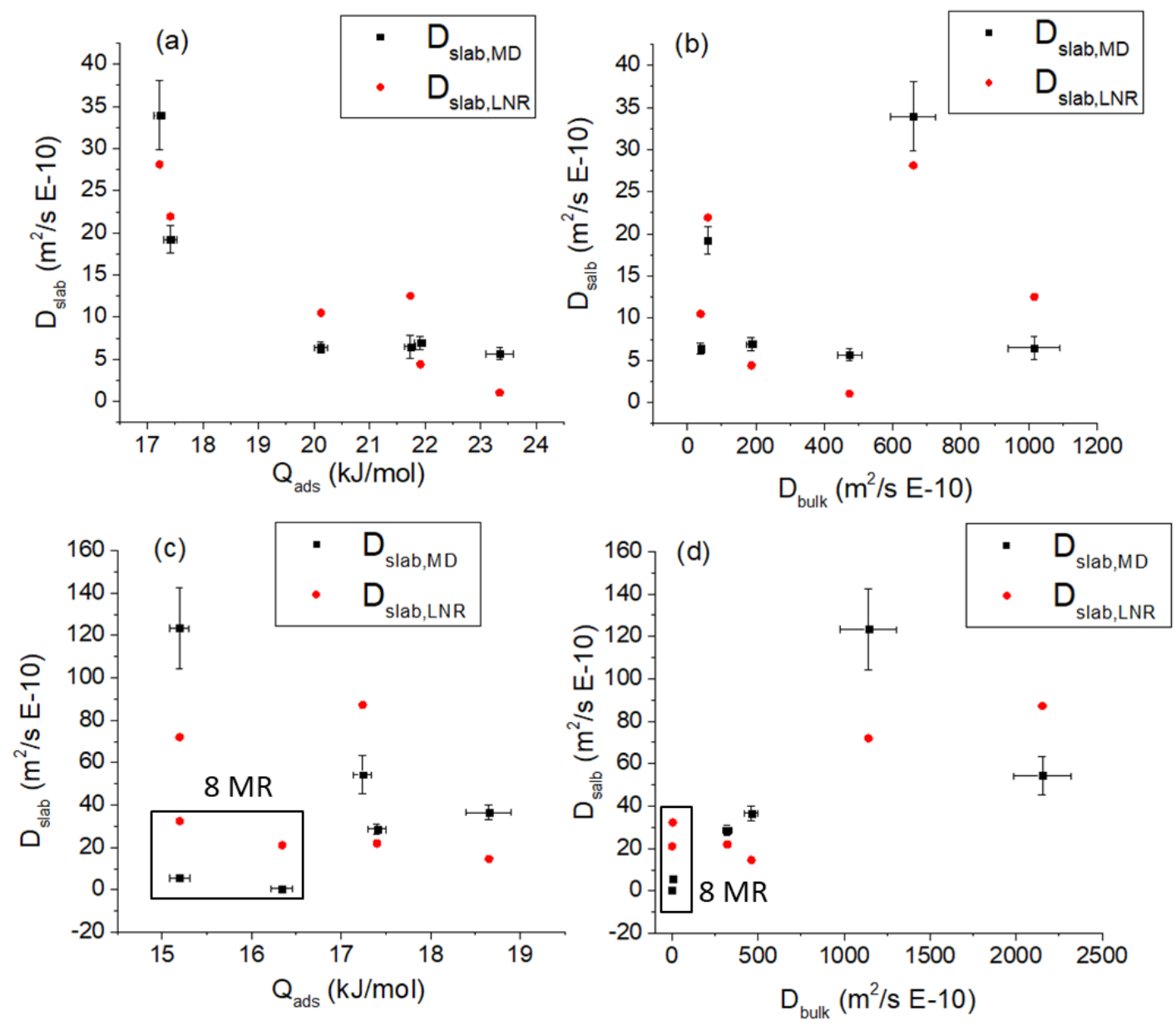

(e)

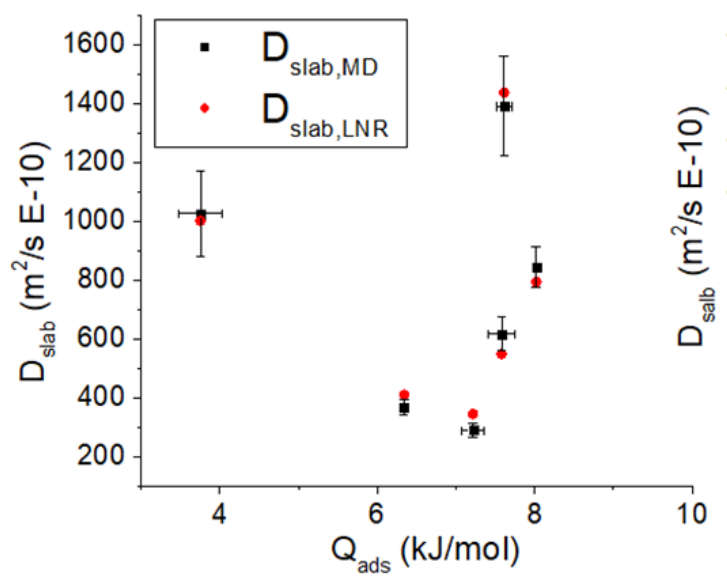

(f)

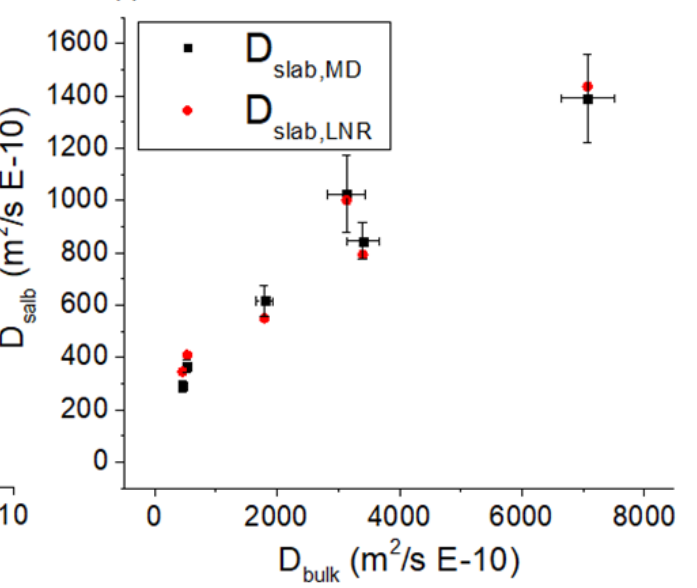

Figure S.19. The $\mathrm{D}_{\text {slab,MD }}$ at $250 \mathrm{~K}$ and $1,689 \mathrm{~Pa}$ and the $\mathrm{D}_{\text {slab,LNR }}$ graphed against $Q_{\text {ads }}$ in (a) $\mathrm{CO}_{2}$, (c) $\mathrm{CH}_{4}$, and (e) $\mathrm{H}_{2}$; graphed against $\mathrm{D}_{\text {bulk }}$ in (b) $\mathrm{CO}_{2}$, (d) $\mathrm{CH}_{4}$, and (f) $\mathrm{H}_{2}$. The $8 \mathrm{MR}$ data is boxed in the $\mathrm{CH}_{4}$ graphs in (c) and (d). 
Table S.10 - Best Fit For $\mathbf{D}_{\text {slab }}$ Estimate

\begin{tabular}{ccccc}
\hline & $\begin{array}{c}x_{1} \\
\text { Unitless }\end{array}$ & $\begin{array}{c}x_{2} \\
\left(\mathrm{~m}^{2} / \mathrm{s} \mathrm{E}-10\right) /(\mathrm{kJ} / \mathrm{mol})\end{array}$ & $\begin{array}{c}x_{3} \\
\mathrm{~m}^{2} / \mathrm{s} \mathrm{E}-10\end{array}$ & $\begin{array}{c}\mathrm{R}^{2} \\
\text { Fit }\end{array}$ \\
\hline $\mathrm{CO}_{2}$ & 0.001787 & -0.83051 & 18.746 & 0.813 \\
$\mathrm{CH}_{4}$ & 0.034845 & -9.7439 & 180.24 & 0.462 \\
$\mathrm{H}_{2}$ & 0.1685 & -58.956 & 694.07 & 0.983
\end{tabular}

The IS bulk and IS $\mathrm{S}_{\text {slab }}$ results in Figure $\mathbf{S . 2 0}$ show that for $\mathrm{CO}_{2} / \mathrm{CH}_{4}$, the $\mathrm{IS}_{\text {slab }}$ increases with IS bulk while the opposite is true for $\mathrm{CO}_{2} / \mathrm{H}_{2}$. For $\mathrm{CO}_{2} / \mathrm{H}_{2}$ separation in the slab, surface resistance reduces $\mathrm{CO}_{2}$ diffusion and gives a preference to $\mathrm{H}_{2}$. For $\mathrm{CO}_{2} / \mathrm{CH}_{4}$ separation in the $10 \mathrm{MR}$ zeolite slabs, there is no clear trend against the bulk diffusivity. This lack of trend is likely because $\mathrm{CH}_{4}$ also has a surface resistance so it does not have quite the kinetic advantage in slab diffusion that $\mathrm{H}_{2}$ has.
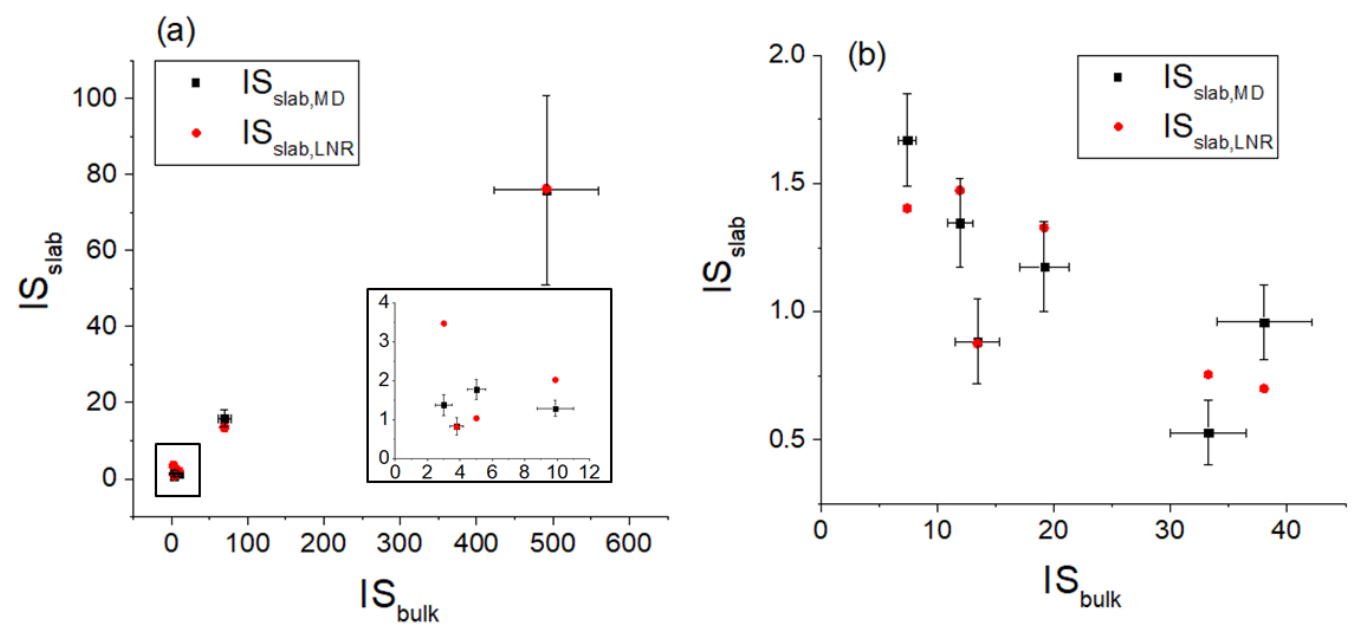

Figure S.20. Ideal selectivity of slab and bulk structures at $250 \mathrm{~K}$ and 1,689 $\mathrm{Pa}$ for (a) $\mathrm{CO}_{2} / \mathrm{CH}_{4}$ with an inset expanding the $10 \mathrm{MR}$ zeolites, and (b) $\mathrm{CO}_{2} / \mathrm{H}_{2}$. 
Table S.11 - Best Fit for $\mathbf{I S}_{\text {slab }}$ Estimate

\begin{tabular}{ccccc}
\hline $\begin{array}{c}\text { Slab Ideal } \\
\text { Selectivity }\end{array}$ & $x_{1}$ & $x_{2}$ & $x_{3}$ & $\mathrm{R}^{2}$ \\
& Unitless & $1 /(\mathrm{kJ} / \mathrm{mol})$ & $1 /(\mathrm{kJ} / \mathrm{mol})$ & \\
\hline $\mathrm{CO}_{2} / \mathrm{CH}_{4}$ & 0.1532 & -1.4462 & 1.8367 & 0.997 \\
$\mathrm{CO}_{2} / \mathrm{H}_{2}$ & -0.040186 & 0.059104 & 0.10573 & 0.707
\end{tabular}

\section{S.12 Raw Data and Graph Data}

Tables S.12.1 to S.12.8 display the raw diffusivity data from our calculations. They are not graphed in the main body of this manuscript but form the foundation for the graphs therein. The loading in nanosheets is the average number of adsorbates in the zeolite phase throughout the simulation. Tables S.12.8 to S.12.27 are the numerical data directly displayed in the main text graphs and are labeled as such. 
Table S.12.1 - $\mathbf{H}_{2}$ Diffusion at High and Low Loadings

\begin{tabular}{ccccccc}
\hline & \multicolumn{3}{c}{ Bulk MFI (010) } & \multicolumn{2}{c}{$2 \mathrm{~nm}$ MFI (010) Slab } \\
\hline $\begin{array}{c}\text { Temperature } \\
\mathrm{K}\end{array}$ & $\begin{array}{c}\text { Loading } \\
\text { molec/uc }\end{array}$ & $\begin{array}{c}\mathrm{D}_{\text {z,zeo }} \\
\mathrm{m}^{2} / \mathrm{s} \mathrm{E}-10\end{array}$ & $\begin{array}{c}\mathrm{Sm} \\
\mathrm{m}^{2} / \mathrm{s} \mathrm{E}-10\end{array}$ & $\begin{array}{c}\text { Loading } \\
\text { molec/uc }\end{array}$ & $\begin{array}{c}\mathrm{D}_{\text {z,zeo }} \\
\mathrm{m}^{2} / \mathrm{s} \mathrm{E}-10\end{array}$ & $\begin{array}{c}\mathrm{Sm} \\
\mathrm{m}^{2} / \mathrm{s} \mathrm{E}-10\end{array}$ \\
\hline 250 & 2.00 & 1796 & 136 & 8.54 & 1022 & 80 \\
300 & 2.00 & 2055 & 154 & 5.79 & 1283 & 100 \\
400 & 2.00 & 1971 & 265 & 3.11 & 1999 & 211 \\
500 & 2.00 & 3381 & 277 & 2.14 & 2216 & 206 \\
250 & 20.00 & 1333 & 138 & 0.37 & 926 & 87 \\
300 & 13.00 & 2131 & 186 & 0.30 & 1288 & 105 \\
400 & 7.00 & 2691 & 251 & 0.22 & 1676 & 121 \\
500 & 4.00 & 2800 & 316 & 0.18 & 2213 & 195
\end{tabular}

Table S.12.2 - $\mathrm{CH}_{4}$ Diffusion at High and Low Loadings

\begin{tabular}{|c|c|c|c|c|c|c|}
\hline \multirow[b]{2}{*}{$\begin{array}{c}\text { Temperature } \\
\mathrm{K}\end{array}$} & \multicolumn{3}{|c|}{ Bulk MFI (010) } & \multicolumn{3}{|c|}{$2 \mathrm{~nm}$ MFI (010) Slab } \\
\hline & $\begin{array}{l}\text { Loading } \\
\text { molec/uc }\end{array}$ & $\begin{array}{c}D_{z, \text { zeo }} \\
\mathrm{m}^{2} / \mathrm{s} \text { E-10 }\end{array}$ & $\begin{array}{c}\mathrm{Sm} \\
\mathrm{m}^{2} / \mathrm{s} \text { E-10 }\end{array}$ & $\begin{array}{l}\text { Loading } \\
\text { molec/uc }\end{array}$ & $\begin{array}{c}D_{z, \text { zeo }} \\
\mathrm{m}^{2} / \mathrm{s} \text { E-10 }\end{array}$ & $\begin{array}{c}\mathrm{sm} \\
\mathrm{m}^{2} / \mathrm{s} \text { E-10 }\end{array}$ \\
\hline 250 & 2.00 & 321 & 25 & 0.95 & 28 & 2 \\
\hline 300 & 2.00 & 349 & 27 & 0.86 & 55 & 6 \\
\hline 400 & 2.00 & 552 & 42 & 0.69 & 156 & 22 \\
\hline 500 & 2.00 & 647 & 52 & 0.55 & 276 & 21 \\
\hline 250 & 33.00 & 292 & 22 & 22.21 & 115 & 10 \\
\hline 300 & 26.00 & 317 & 23 & 15.36 & 137 & 11 \\
\hline 400 & 13.00 & 559 & 39 & 7.44 & 226 & 20 \\
\hline 500 & 6.00 & 720 & 57 & 4.24 & 273 & 47 \\
\hline
\end{tabular}


Table S.12.3 - $\mathrm{CO}_{2}$ Diffusion at High and Low Loadings

\begin{tabular}{ccccccc}
\hline & \multicolumn{3}{c}{ Bulk MFI (010) } & \multicolumn{2}{c}{$2 \mathrm{~nm}$ MFI (010) Slab } \\
\hline Temperature & $\begin{array}{c}\text { Loading } \\
\text { molec/uc }\end{array}$ & $\begin{array}{c}\mathrm{D}_{\text {z,zeo }} \\
\mathrm{m}^{2} / \mathrm{s} \mathrm{E}-10\end{array}$ & $\begin{array}{c}\mathrm{Sm} \\
\mathrm{m}^{2} / \mathrm{s} \mathrm{E}-10\end{array}$ & $\begin{array}{c}\text { Loading } \\
\text { molec/uc }\end{array}$ & $\begin{array}{c}\mathrm{D}_{\text {z,zeo }} \\
\mathrm{m}^{2} / \mathrm{s} \mathrm{E}-10\end{array}$ & $\mathrm{~m}^{2} / \mathrm{s}$ E-10 \\
\hline 250 & 2.00 & 188 & 15 & 0.99 & 7 & 1 \\
300 & 2.00 & 225 & 18 & 0.96 & 20 & 2 \\
400 & 2.00 & 339 & 29 & 0.84 & 80 & 6 \\
500 & 2.00 & 434 & 32 & 0.69 & 155 & 10 \\
250 & 44.00 & 85 & 7 & 39.75 & 38 & 3 \\
300 & 38.00 & 160 & 13 & 27.67 & 61 & 7 \\
400 & 24.00 & 286 & 22 & 12.80 & 111 & 8 \\
500 & 12.00 & 421 & 29 & 6.87 & 147 & 15
\end{tabular}

Table S.12.4 - Ethene Diffusion at High and Low Loadings

\begin{tabular}{ccccccc}
\hline & \multicolumn{3}{c}{ Bulk MFI (010) } & \multicolumn{2}{c}{$2 \mathrm{~nm}$ MFI (010) Slab } \\
\hline Temperature & Loading & $\mathrm{D}_{\text {z,zeo }}$ & $\mathrm{Sm}$ & Loading & $\mathrm{D}_{\text {z,zeo }}$ & $\mathrm{Sm}$ \\
$\mathrm{K}$ & molec/uc & $\mathrm{m}^{2} / \mathrm{s} \mathrm{E}-10$ & $\mathrm{~m}^{2} / \mathrm{s} \mathrm{E}-10$ & molec/uc & $\mathrm{m}^{2} / \mathrm{s} \mathrm{E}-10$ & $\mathrm{~m}^{2} / \mathrm{s} \mathrm{E-10}$ \\
\hline 250 & 2 & 179 & 9 & 0.99 & 4 & 0 \\
300 & 2 & 247 & 12 & 0.97 & 14 & 1 \\
400 & 2 & 357 & 18 & 0.85 & 68 & 4 \\
500 & 2 & 391 & 22 & 0.67 & 155 & 7 \\
250 & 32 & 238 & 12 & 16.34 & 42 & 2 \\
300 & 30 & 259 & 14 & 17.75 & 78 & 4 \\
400 & 22 & 204 & 11 & 11.48 & 112 & 6 \\
500 & 13 & 326 & 17 & 6.02 & 151 & 8
\end{tabular}


Table S.12.5 - Ethane Diffusion at High and Low Loadings

\begin{tabular}{ccccccc}
\hline & \multicolumn{3}{c}{ Bulk MFI (010) } & \multicolumn{2}{c}{$2 \mathrm{~nm}$ MFI (010) Slab } \\
\hline Temperature & Loading & $\mathrm{D}_{\text {z,zeo }}$ & Sm & Loading & $\mathrm{D}_{\text {z,zeo }}$ & $\mathrm{sm}$ \\
$\mathrm{K}$ & molec/uc & $\mathrm{m}^{2} / \mathrm{s} \mathrm{E}-10$ & $\mathrm{~m}^{2} / \mathrm{s} \mathrm{E}-10$ & molec/uc & $\mathrm{m}^{2} / \mathrm{s} \mathrm{E-10}$ & $\mathrm{m}^{2} / \mathrm{s} \mathrm{E-10}$ \\
\hline 250 & 2 & 163 & 10 & 1.00 & 1 & 0 \\
300 & 2 & 232 & 12 & 0.98 & 9 & 1 \\
400 & 2 & 336 & 17 & 0.88 & 50 & 3 \\
500 & 2 & 418 & 23 & 0.71 & 115 & 6 \\
250 & 32 & 210 & 14 & 17.30 & 37 & 3 \\
300 & 30 & 170 & 9 & 19.11 & 60 & 4 \\
400 & 22 & 138 & 7 & 11.71 & 84 & 5 \\
500 & 13 & 281 & 15 & 6.74 & 122 & 6
\end{tabular}

Table S.12.6 - Propene Diffusion at High and Low Loadings

\begin{tabular}{ccccccc}
\hline & \multicolumn{3}{c}{ Bulk MFI (010) } & \multicolumn{3}{c}{$2 \mathrm{~nm}$ MFI (010) Slab } \\
\hline Temperature & Loading & $\mathrm{D}_{\text {z,zeo }}$ & $\mathrm{sm}$ & Loading & $\mathrm{D}_{\text {z,zeo }}$ & $\mathrm{Sm}$ \\
$\mathrm{K}$ & molec/uc & $\mathrm{m}^{2} / \mathrm{s} \mathrm{E}-10$ & $\mathrm{~m}^{2} / \mathrm{s} \mathrm{E}-10$ & molec/uc & $\mathrm{m}^{2} / \mathrm{s} \mathrm{E-10}$ & $\mathrm{m}^{2} / \mathrm{s}$ E-10 \\
\hline 250 & 2 & 106 & 6 & 1.00 & 0.3 & 0.1 \\
300 & 2 & 159 & 8 & 0.99 & 3.0 & 0.3 \\
400 & 2 & 132 & 27 & 0.94 & 26.6 & 3.4 \\
500 & 2 & 259 & 28 & 0.78 & 69.3 & 7.8 \\
250 & 24 & 3 & 0 & 10.79 & 8.0 & 0.4 \\
300 & 23 & 26 & 3 & 11.13 & 21.2 & 2.7 \\
400 & 21 & 62 & 8 & 13.41 & 44.9 & 4.5 \\
500 & 15 & 161 & 17 & 7.51 & 95.0 & 9.6
\end{tabular}


Table S.12.7 - Propane Diffusion at High and Low Loadings

\begin{tabular}{ccccccc}
\hline & \multicolumn{3}{c}{ Bulk MFI (010) } & \multicolumn{3}{c}{$2 \mathrm{~nm} \mathrm{MFI} \mathrm{(010)} \mathrm{Slab}$} \\
\hline $\begin{array}{c}\text { Temperature } \\
(\mathrm{K})\end{array}$ & $\begin{array}{c}\text { Loading } \\
\text { molec/uc }\end{array}$ & $\begin{array}{c}\mathrm{D}_{\text {z,zeo }} \\
\mathrm{m}^{2} / \mathrm{s} \mathrm{E}-10\end{array}$ & $\begin{array}{c}\mathrm{Sm} \\
\mathrm{m}^{2} / \mathrm{s} \mathrm{E}-10\end{array}$ & $\begin{array}{c}\text { Loading } \\
\text { molec/uc }\end{array}$ & $\begin{array}{c}\mathrm{D}_{z, \text { zeo }} \\
\mathrm{m}^{2} / \mathrm{s} \mathrm{E}-10\end{array}$ & $\begin{array}{c}\mathrm{Sm} \\
\mathrm{m}^{2} / \mathrm{s} \mathrm{E}-10\end{array}$ \\
\hline 250 & 2 & 86 & 6 & 1.00 & 0.2 & 0.1 \\
300 & 2 & 159 & 9 & 1.00 & 1.9 & 0.3 \\
400 & 2 & 130 & 37 & 0.95 & 19.1 & 2.1 \\
500 & 2 & 230 & 21 & 0.79 & 55.6 & 5.4 \\
250 & 24 & 1 & 0 & 10.81 & 7.4 & 0.4 \\
300 & 23 & 23 & 2 & 11.15 & 17.7 & 2.2 \\
400 & 21 & 71 & 8 & 13.85 & 45.2 & 5.1 \\
500 & 14 & 143 & 15 & 7.50 & 74.3 & 7.7
\end{tabular}

Table S.12.8 - Diffusion in a $14 \mathrm{~nm}$ MFI (010) Slab at $250 \mathrm{~K}$ and 1 molec/uc

\begin{tabular}{cccc}
\hline Adsorbate & $\begin{array}{c}\text { Loading } \\
\text { molec/uc }\end{array}$ & $\begin{array}{c}\mathrm{D}_{\text {z,zeo }} \\
\mathrm{m}^{2} / \mathrm{s} \mathrm{E}-10\end{array}$ & $\begin{array}{c}\mathrm{Sm} \\
\mathrm{m}^{2} / \mathrm{s} \mathrm{E}-10\end{array}$ \\
\hline $\mathrm{H}_{2}$ & 3.86 & 1470 & 72 \\
$\mathrm{CH}_{4}$ & 4.96 & 96 & 5 \\
$\mathrm{CO}_{2}$ & 4.99 & 41 & 2 \\
Ethane & 5.00 & 6 & 1 \\
Propane & 5.00 & 0.5 & 0.1
\end{tabular}


Table S.12.9 - Surface Resistance in $2 \mathrm{~nm}$ MFI at 1 molec/uc (Figure 2(a))

\begin{tabular}{cccccccc}
\hline & \multicolumn{7}{c}{ Surface Resistance (nm) } \\
Temperature $(\mathrm{K})$ & $\mathrm{H}_{2}$ & $\mathrm{CH}_{4}$ & $\mathrm{CO}_{2}$ & Ethene & Ethane & Propene & Propane \\
\hline 250 & 4.2 & 22.4 & 57.3 & 103.4 & 235.2 & 827.3 & 1537.1 \\
300 & 3.3 & 12.6 & 20.9 & 34.5 & 56.3 & 114.4 & 183.7 \\
400 & 4.7 & 6.3 & 7.3 & 9.6 & 12.9 & 8.2 & 12.1 \\
500 & 4.3 & 2.9 & 4.1 & 3.5 & 5.7 & 6.3 & 7.1 \\
\cline { 2 - 7 } & 0.8 & 2.8 & 8.4 & 7.7 & 23.6 & 286.7 & 551.1 \\
250 & 0.6 & 2.0 & 3.0 & 3.0 & 5.1 & 14.2 & 29.4 \\
300 & 1.1 & 1.4 & 1.1 & 0.9 & 1.1 & 2.5 & 4.4 \\
400 & 0.8 & 0.6 & 0.6 & 0.4 & 0.6 & 1.3 & 1.2 \\
500 & \multicolumn{7}{c}{ Surface Resistance Error (nm) }
\end{tabular}

Table S.12.10 - Surface Resistance in 2 nm MFI at High Loading (Figure 2(b))

\begin{tabular}{|c|c|c|c|c|c|c|c|}
\hline \multirow[b]{2}{*}{ Temperature (K) } & \multicolumn{7}{|c|}{ Surface Resistance (nm) } \\
\hline & $\mathrm{H}_{2}$ & $\mathrm{CH}_{4}$ & $\mathrm{CO}_{2}$ & Ethene & Ethane & Propene & Propane \\
\hline 250 & 0.7 & 3.4 & 2.7 & 10.2 & 10.3 & -1.4 & -1.8 \\
\hline 300 & 1.4 & 2.9 & 3.5 & 5.1 & 4.0 & 0.5 & 0.7 \\
\hline 400 & 0.8 & 3.2 & 3.4 & 1.8 & 1.4 & 0.9 & 1.2 \\
\hline \multirow[t]{2}{*}{500} & 0.6 & 3.6 & 4.1 & 2.6 & 2.8 & 1.5 & 2.0 \\
\hline & \multicolumn{7}{|c|}{ Surface Resistance Error (nm) } \\
\hline 250 & 0.4 & 0.6 & 0.6 & 0.9 & 1.3 & 0.1 & 0.1 \\
\hline 300 & 0.4 & 0.6 & 0.8 & 0.5 & 0.5 & 0.4 & 0.5 \\
\hline 400 & 0.4 & 0.6 & 0.6 & 0.3 & 0.3 & 0.5 & 0.5 \\
\hline 500 & 0.4 & 1.1 & 0.8 & 0.4 & 0.4 & 0.5 & 0.6 \\
\hline
\end{tabular}


Table S.12.11 - Surface Resistance vs. Heat of Adsorption (Figure 3)

\begin{tabular}{cccccccc}
\hline & \multicolumn{8}{c}{ Surface Resistance $(\mathrm{nm})$} \\
Temperature (K) & $\mathrm{H}_{2}$ & $\mathrm{CH}_{4}$ & $\mathrm{CO}_{2}$ & Ethene & Ethane & Propene & Propane \\
250 & 0.7 & 3.4 & 2.7 & 10.2 & 10.3 & -1.4 & -1.8 \\
& & \multicolumn{7}{c}{ Surface Resistance Error $(\mathrm{nm})$} \\
250 & 0.4 & 0.6 & 0.6 & 0.9 & 1.3 & 0.1 & 0.1 \\
\hline & 7.6 & 16.3 & 21.8 & 23.2 & 26.0 & 31.2 & 33.7
\end{tabular}

Table S.12.12 - $C_{2}$ Ideal Selectivity in MFI (010) at 1 molec/uc (Figure 4(a))

\begin{tabular}{ccccc}
\hline & \multicolumn{2}{c}{ Ethane/Ethene - Bulk } & \multicolumn{2}{c}{ Ethane/Ethene - Slab } \\
Temperature (K) & IS & Error & IS & Error \\
\hline 250 & 1.1 & 0.1 & 2.7 & 0.6 \\
300 & 1.1 & 0.1 & 1.6 & 0.2 \\
400 & 1.0 & 0.1 & 1.3 & 0.1 \\
500 & 0.9 & 0.1 & 1.2 & 0.1
\end{tabular}

Table S.12.13 - $C_{2}$ Ideal Selectivity in MFI (010) at High Loading (Figure 4(b))

\begin{tabular}{ccccc}
\hline & \multicolumn{2}{c}{ Ethane/Ethene - Bulk } & \multicolumn{2}{c}{ Ethane/Ethene - Slab } \\
Temperature (K) & IS & Error & IS & Error \\
\hline 250 & 1.1 & 0.1 & 0.9 & 0.1 \\
300 & 1.5 & 0.1 & 1.2 & 0.1 \\
400 & 1.4 & 0.1 & 1.3 & 0.1 \\
500 & 1.1 & 0.1 & 1.1 & 0.1
\end{tabular}

Table S.12.14 - C 3 Ideal Selectivity in MFI (010) at 1 molec/uc (Figure 4(c))

\begin{tabular}{ccccc}
\hline & \multicolumn{2}{c}{ Propane/Propene - Bulk } & \multicolumn{2}{c}{ Propene/Propane - Slab } \\
Temperature (K) & IS & Error & IS & Error \\
\hline 250 & 1.2 & 0.1 & 2.3 & 1.1 \\
300 & 1.0 & 0.1 & 1.6 & 0.3 \\
400 & 1.0 & 0.4 & 1.4 & 0.2 \\
500 & 1.1 & 0.2 & 1.2 & 0.2
\end{tabular}


Table S.12.15 - C 3 Ideal Selectivity in MFI (010) at High Loading (Figure 4(d))

\begin{tabular}{ccccc}
\hline & \multicolumn{2}{c}{ Propane/Propene - Bulk } & \multicolumn{2}{c}{ Propene/Propane - Slab } \\
Temperature (K) & IS & Error & IS & Error \\
\hline 250 & 2.1 & 0.5 & 1.1 & 0.1 \\
300 & 1.1 & 0.1 & 1.2 & 0.2 \\
400 & 0.9 & 0.1 & 1.0 & 0.1 \\
500 & 1.3 & 0.1 & 1.3 & 0.2
\end{tabular}

Table S.12.16 $-\mathrm{H}_{2} / \mathrm{CO}_{2}$ Ideal Selectivity in MFI (010) at $1 \mathrm{molec} / \mathrm{uc}$ (Figure 5(a))

\begin{tabular}{ccccc}
\hline & \multicolumn{2}{c}{$\mathrm{H}_{2} / \mathrm{CO}_{2}-$ Bulk } & \multicolumn{2}{c}{$\mathrm{H}_{2} / \mathrm{CO}_{2}-$ Slab } \\
Temperature (K) & IS & Error & IS & Error \\
\hline 250 & 0.052 & 0.006 & 0.851 & 0.126 \\
300 & 0.138 & 0.015 & 1.140 & 0.149 \\
400 & 0.330 & 0.052 & 1.492 & 0.156 \\
500 & 0.974 & 0.108 & 1.861 & 0.206
\end{tabular}

Table S.12.17 - $\mathrm{CH}_{4} / \mathrm{CO}_{2}$ Ideal Selectivity in MFI (010) at High Loading (Figure 5(b))

\begin{tabular}{ccccc}
\hline & \multicolumn{2}{c}{$\mathrm{CH}_{4} / \mathrm{CO}_{2}-$ Bulk } & \multicolumn{2}{c}{$\mathrm{CH}_{4} / \mathrm{CO}_{2}-\mathrm{Slab}$} \\
Temperature (K) & IS & Error & IS & Error \\
\hline 250 & 2.1 & 0.5 & 1.1 & 0.1 \\
300 & 1.1 & 0.1 & 1.2 & 0.2 \\
400 & 0.9 & 0.1 & 1.0 & 0.1 \\
500 & 1.3 & 0.1 & 1.3 & 0.2
\end{tabular}


Table S.12.18 - Surface Resistance at 2 bar 300 K (Figure 6(a))

\begin{tabular}{|c|c|c|c|}
\hline \multirow[b]{2}{*}{ Slab Height (nm) } & \multicolumn{3}{|c|}{ Surface Resistance $(\mathrm{nm})$} \\
\hline & $\mathrm{H}_{2}$ & $\mathrm{CH}_{4}$ & $\mathrm{CO}_{2}$ \\
\hline 1 & 1.1 & 5.0 & 6.9 \\
\hline 2 & 1.9 & 9.1 & 12.1 \\
\hline 4 & 1.3 & 8.9 & 16.8 \\
\hline 10 & 1.2 & 8.2 & 16.1 \\
\hline \multirow[t]{2}{*}{14} & 1.6 & 10.6 & 17.3 \\
\hline & Surfac & Resistan & Error (nm) \\
\hline 1 & 0.2 & 0.7 & 0.6 \\
\hline 2 & 0.4 & 2.0 & 1.3 \\
\hline 4 & 0.4 & 1.6 & 1.4 \\
\hline 10 & 0.8 & 2.3 & 1.8 \\
\hline 14 & 1.1 & 2.9 & 2.1 \\
\hline
\end{tabular}

Table S.12.19 - Surface Resistance at 2 bar 400 K (Figure 6(b))

\begin{tabular}{cccc}
\hline & \multicolumn{3}{c}{ Surface Resistance $(\mathrm{nm})$} \\
Slab Height (nm) & $\mathrm{H}_{2}$ & $\mathrm{CH}_{4}$ & $\mathrm{CO}_{2}$ \\
\hline 1 & 0.6 & 3.6 & 3.7 \\
2 & 0.3 & 3.6 & 6.0 \\
4 & 0.7 & 4.3 & 6.3 \\
10 & 0.0 & 6.0 & 6.8 \\
14 & 1.6 & 3.1 & 6.3 \\
& Surface & Resistance & Error (nm) \\
1 & 0.2 & 0.4 & 0.4 \\
2 & 0.3 & 0.6 & 0.8 \\
4 & 0.3 & 0.8 & 0.9 \\
10 & 0.7 & 1.5 & 1.5 \\
14 & 1.1 & 1.5 & 1.8
\end{tabular}


Table S.12.20 - Surface Resistance at 20 bar 300 K (Figure 6(c))

\begin{tabular}{|c|c|c|c|}
\hline \multirow[b]{2}{*}{ Slab Height (nm) } & \multicolumn{3}{|c|}{ Surface Resistance (nm) } \\
\hline & $\mathrm{H}_{2}$ & $\mathrm{CH}_{4}$ & $\mathrm{CO}_{2}$ \\
\hline 1 & 0.9 & 3.7 & 3.6 \\
\hline 2 & 1.7 & 4.1 & 4.4 \\
\hline 4 & 1.8 & 5.0 & 2.8 \\
\hline 10 & 1.3 & 4.9 & 3.7 \\
\hline \multirow[t]{2}{*}{14} & 0.3 & 2.3 & 2.7 \\
\hline & Surfac & Resistar & Error $(\mathrm{nm})$ \\
\hline 1 & 0.2 & 0.4 & 0.3 \\
\hline 2 & 0.5 & 0.6 & 0.5 \\
\hline 4 & 0.5 & 0.8 & 0.5 \\
\hline 10 & 0.9 & 1.4 & 0.9 \\
\hline 14 & 11 & 15 & 11 \\
\hline
\end{tabular}

Table S.12.21 - Surface Resistance at 20 bar 400 K (Figure 6(d))

\begin{tabular}{|c|c|c|c|}
\hline \multirow[b]{2}{*}{ Slab Height $(\mathrm{nm})$} & \multicolumn{3}{|c|}{ Surface Resistance (nm) } \\
\hline & $\mathrm{H}_{2}$ & $\mathrm{CH}_{4}$ & $\mathrm{CO}_{2}$ \\
\hline 1 & 1.1 & 3.5 & 3.2 \\
\hline 2 & 1.5 & 4.0 & 3.9 \\
\hline 4 & 1.6 & 4.3 & 3.3 \\
\hline 10 & 2.6 & 4.8 & 3.8 \\
\hline \multirow[t]{2}{*}{14} & 2.7 & 4.6 & 4.6 \\
\hline & Surfac & Resistan & Error $(\mathrm{nm})$ \\
\hline 1 & 0.2 & 0.4 & 0.4 \\
\hline 2 & 0.3 & 0.6 & 0.5 \\
\hline 4 & 0.5 & 0.8 & 0.6 \\
\hline 10 & 1.1 & 1.4 & 1.1 \\
\hline 14 & 1.3 & 1.7 & 1.6 \\
\hline
\end{tabular}


Table S.12.22 - Surface Resistance vs. Height in MFI Slabs (Figure 7 of Main Text)

\begin{tabular}{|c|c|c|c|c|c|}
\hline \multirow[b]{2}{*}{ Slab Height (nm) } & \multicolumn{5}{|c|}{ Surface Resistance (nm) } \\
\hline & $\mathrm{H}_{2}$ & $\mathrm{CH}_{4}$ & $\mathrm{CO}_{2}$ & Ethane & Propane \\
\hline 2 & 2 & 23 & 58 & 265 & 1181 \\
\hline \multirow[t]{2}{*}{10} & 2 & 24 & 37 & 256 & 1780 \\
\hline & \multicolumn{5}{|c|}{ Surface Resistance Error (nm) } \\
\hline 2 & 1 & 3 & 8 & 56 & 554 \\
\hline 10 & 1 & 3 & 5 & 65 & 549 \\
\hline
\end{tabular}

Table S.12.23 - Surface Resistance in Different Frameworks (Figure 8(a))

\begin{tabular}{cccc}
\hline & \multicolumn{3}{c}{ Surface Resistance $(\mathrm{nm})$} \\
Framework & $\mathrm{H}_{2}$ & $\mathrm{CH}_{4}$ & $\mathrm{CO}_{2}$ \\
\hline LTA & 1.1 & -0.3 & 5.4 \\
CHA & 1.1 & 0.4 & 10.1 \\
AFI & 4.6 & 18.6 & 41.5 \\
MFI & 4.2 & 22.4 & 57.3 \\
AEL & 6.9 & 26.4 & 189.4 \\
ATO & 11.1 & 105.3 & 425.8 \\
& Surface & Resistance & Error $(\mathrm{nm})$ \\
LTA & 0.4 & 0.3 & 0.9 \\
CHA & 0.3 & 0.8 & 1.5 \\
AFI & 1.2 & 4.4 & 6.8 \\
MFI & 0.8 & 2.8 & 8.4 \\
AEL & 1.0 & 3.7 & 28.5 \\
ATO & 1.9 & 19.9 & 94.3
\end{tabular}


Table S.12.24 - $\mathrm{CO}_{2} \mathrm{D}_{0, \text { bulk, }} \mathrm{D}_{0, \text { slab, and }} \mathrm{Q}_{\text {ads }}$ in Different Frameworks (Figures 8(b) and S.19)

\begin{tabular}{ccccc}
\hline Framework & $\begin{array}{c}\mathrm{D}_{0, \text { bulk }} \\
\mathrm{m}^{2} / \mathrm{s} \mathrm{E}-10\end{array}$ & $\begin{array}{c}\mathrm{D}_{0, \text { slab,MD }} \\
\mathrm{m}^{2} / \mathrm{s} \mathrm{E}-10\end{array}$ & $\begin{array}{c}\mathrm{Q}_{\text {ads }} \\
\mathrm{kJ} / \mathrm{mol}\end{array}$ & $\begin{array}{c}\mathrm{D}_{0, \text { slab,LNR }} \\
\mathrm{m}^{2} / \mathrm{s} \mathrm{E}-10\end{array}$ \\
\hline MFI & 188 & 7 & 21.9 & 4 \\
AEL & 474 & 6 & 23.3 & 1 \\
ATO & 1015 & 6 & 21.7 & 13 \\
AFI & 661 & 34 & 17.2 & 28 \\
LTA & 60 & 19 & 17.4 & 22 \\
CHA & 39 & 6 & 20.1 & 10 \\
& & Errors & & \\
MFI & 15 & 1 & 0.1 & \\
AEL & 36 & 1 & 0.3 & \\
ATO & 76 & 1 & 0.1 & \\
AFI & 65 & 4 & 0.1 & \\
LTA & 4 & 2 & 0.1 & \\
CHA & 2 & 1 & 0.1 &
\end{tabular}

Table S.12.25 - $\mathrm{CH}_{4} \mathrm{D}_{0, \text { bulk, }}, \mathrm{D}_{0, \text { slab, }}$ and $Q_{\text {ads }}$ in Different Frameworks (Figures 8(c) and S.19)

\begin{tabular}{ccccc}
\hline Framework & $\begin{array}{c}\mathrm{D}_{0, \text { bulk }} \\
\mathrm{m}^{2} / \mathrm{s} \mathrm{E}-10\end{array}$ & $\begin{array}{c}\mathrm{D}_{0, \text { slab,MD }} \\
\mathrm{m}^{2} / \mathrm{s} \mathrm{E}-10\end{array}$ & $\begin{array}{c}\mathrm{Q}_{\text {ads }} \\
\mathrm{kJ} / \mathrm{mol}\end{array}$ & $\begin{array}{c}\mathrm{D}_{0, \text { slab,LNR }} \\
\mathrm{m}^{2} / \mathrm{s} \mathrm{E}-10\end{array}$ \\
\hline MFI & 321 & 29 & 17.4 & 22 \\
AEL & 462 & 37 & 18.7 & 15 \\
ATO & 2152 & 54 & 17.2 & 87 \\
AFI & 1142 & 123 & 15.2 & 72 \\
LTA & 5 & 6 & 15.2 & 32 \\
CHA & 1 & 1 & 16.3 & 21 \\
& & Errors & & \\
MFI & 25 & 2 & 0.6 & \\
AEL & 40 & 4 & 0.4 & \\
ATO & 167 & 9 & 0.3 & \\
AFI & 163 & 19 & 0.4 & \\
LTA & 0.5 & 0.6 & 0.3 & \\
CHA & 0.1 & 0.2 & 0.5 &
\end{tabular}


Table S.12.26 - $\mathrm{H}_{2} \mathrm{D}_{0, \text { bulk }}, D_{0, \text { slab}}$, and $Q_{\text {ads }}$ in Different Frameworks (Figures 3.8(d) and S.19)

\begin{tabular}{ccccc}
\hline Framework & $\begin{array}{c}\mathrm{D}_{0, \text { bulk }} \\
\mathrm{m}^{2} / \mathrm{s} \mathrm{E}-10\end{array}$ & $\begin{array}{c}\mathrm{D}_{0, \text { slab,MD }} \\
\mathrm{m}^{2} / \mathrm{s} \mathrm{E}-10\end{array}$ & $\begin{array}{c}\text { Qads } \\
\mathrm{kJ} / \mathrm{mol}\end{array}$ & $\begin{array}{c}\mathrm{D}_{0, \text { slab,LNR }} \\
\mathrm{m}^{2} / \mathrm{s} \mathrm{E}-10\end{array}$ \\
\hline MFI & 1796 & 617 & 7.6 & 550 \\
AEL & 3397 & 845 & 8.0 & 794 \\
ATO & 7068 & 1390 & 7.6 & 1436 \\
AFI & 3134 & 1025 & 3.8 & 1001 \\
LTA & 534 & 368 & 6.3 & 410 \\
CHA & 453 & 290 & 7.2 & 345 \\
& & Errors & & \\
MFI & 136 & 58 & 0.6 & \\
AEL & 260 & 70 & 0.4 & \\
ATO & 436 & 170 & 0.3 & \\
AFI & 306 & 146 & 0.4 & \\
LTA & 38 & 25 & 0.3 & \\
CHA & 31 & 23 & 0.5 &
\end{tabular}

Table S.12.27 - Slab Ideal Selectivity (Figure 9 of Main Text)

\begin{tabular}{ccccc}
\hline Framework & $\begin{array}{c}\mathrm{MD} \\
\mathrm{CO}_{2} / \mathrm{CH}_{4}\end{array}$ & $\begin{array}{c}\mathrm{LNR} \\
\mathrm{CO}_{2} / \mathrm{CH}_{4}\end{array}$ & $\begin{array}{c}\mathrm{MD} \\
\mathrm{CO}_{2} / \mathrm{H}_{2}\end{array}$ & $\begin{array}{c}\mathrm{LNR} \\
\mathrm{CO}_{2} / \mathrm{H}_{2}\end{array}$ \\
\hline MFI & 1.8 & 1.0 & 1.2 & 1.3 \\
AEL & 1.3 & 2.0 & 1.0 & 0.7 \\
ATO & 0.8 & 0.8 & 0.5 & 0.8 \\
AFI & 1.4 & 3.5 & 0.9 & 0.9 \\
LTA & 15.9 & 13.4 & 1.7 & 1.4 \\
CHA & 75.9 & 76.2 & 1.3 & 1.5 \\
& \multicolumn{4}{c}{ Errors } \\
MFI & 0.3 & & 0.2 & \\
AEL & 0.2 & & 0.1 & \\
ATO & 0.2 & & 0.1 & \\
AFI & 0.3 & & 0.2 & \\
LTA & 2.1 & & 0.2 & \\
CHA & 25.0 & & 0.2 &
\end{tabular}




\section{S.13 Software}

-Vienna Ab Initio Simulation Package (VASP 5.4.4): ${ }^{39}$ used for generating DFT energies for $\mathrm{CO}_{2}$ and $\mathrm{H}_{2}$ force field fitting.

-Large-scale Atomic/Molecular Massively Parallel Simulator (LAMMPS) version 08/22/2018:40,

${ }^{41}$ used for all equilibrium molecular dynamics simulations.

-RASPA 2014 (Version 2.0): ${ }^{42}$ used for GCMC simulations to generate isotherms and load unit cells.

-Pymatgen 4.4.043 and Atomic Simulation Environment (ASE) 3.11.10:44 used to read unit cells into our python file that generated the Hill Sauer data file.

$-2 \mathrm{D}$ nanosheet database: ${ }^{45}$ nanosheets used in the study were downloaded from the Knio et al. database.

-Matlab R2016b (9.1.0.441655), September 7, 2016: ${ }^{46}$ the fitlm() function was used to predict diffusivities and ideal selectivities for slabs of six different frameworks. 


\section{S.14 Supporting Information References}

(1) Boulfelfel, S. E.; Ravikovitch, P. I.; Koziol, L.; Sholl, D. S. Improved Hill-Sauer force field for accurate description of pores in 8-ring zeolites. J. Phys. Chem. C. 2016, 120(26), 14140-14148.

(2) Plimpton, S.; Crozier, P.; Thompson, A. LAMMPS-large-scale atomic/molecular massively parallel simulator. Sandia National Laboratories 2007, 18.

(3) Hill, J.-R.; Sauer, J. Molecular mechanics potential for silica and zeolite catalysts based on ab initio calculations. 2. Aluminosilicates. J. Phys. Chem. 1995, 99(23), 9536-9550.

(4) Boulfelfel, S. E.; Ravikovitch, P. I.; Sholl, D. S. Modeling diffusion of linear hydrocarbons in silica zeolite LTA using transition path sampling. J. Phys. Chem. C. 2015, 119(27), 15643-15653.

(5) Fang, H.; Kamakoti, P.; Zang, J.; Cundy, S.; Paur, C.; Ravikovitch, P. I.; Sholl, D. S. Prediction of $\mathrm{CO}_{2}$ Adsorption Properties in Zeolites Using Force Fields Derived from Periodic DispersionCorrected DFT Calculations. J. Phys. Chem. C. 2012, 116(19), 10692-10701.

(6) Fang, H. J.; Awati, R.; Boulfelfel, S. E.; Ravikovitch, P. I.; Sholl, D. S. First-PrinciplesDerived Force Fields for $\mathrm{CH}_{4}$ Adsorption and Diffusion in Siliceous Zeolites. J. Phys. Chem. C. 2018, 122(24), 12880-12891.

(7) Manz, T. A.; Sholl, D. S. Chemically Meaningful Atomic Charges That Reproduce the Electrostatic Potential in Periodic and Nonperiodic Materials. J. Chem. Theory Comput. 2010, 6(8), 2455-2468.

(8) Watanabe, T.; Manz, T. A.; Sholl, D. S. Accurate Treatment of Electrostatics during Molecular Adsorption in Nanoporous Crystals without Assigning Point Charges to Framework Atoms. $J$. Phys. Chem. C. 2011, 115(11), 4824-4836.

(9) Manz, T. A.; Sholl, D. S. Methods for Computing Accurate Atomic Spin Moments for Collinear and Noncollinear Magnetism in Periodic and Nonperiodic Materials. J. Chem. Theory Comput. 2011, 7(12), 4146-4164.

(10) Harris, J. G.; Yung, K. H. Carbon dioxide's liquid-vapor coexistence curve and critical properties as predicted by a simple molecular model. J. Phys. Chem. 1995, 99(31), 12021-12024.

(11) Boulfelfel, S. E.; Ravikovitch, P. I.; Koziol, L.; Sholl, D. S. Improved Hill-Sauer Force Field for Accurate Description of Pores in 8-Ring Zeolites. J. Phys. Chem. C. 2016, 120(26), 1414014148.

(12) Hill, J. R.; Sauer, J. Molecular Mechanics Potential for Silica and Zeolite Catalysts Based on Ab-Initio Calculations .2. Aluminosilicates. J. Phys. Chem. 1995, 99(23), 9536-9550.

(13) Yang, Q. Y.; Xu, Q.; Liu, B.; Zhong, C. L.; Smit, B. Molecular Simulation of $\mathrm{CO}_{2} / \mathrm{H}_{2}$ Mixture Separation in Metal-organic Frameworks: Effect of Catenation and Electrostatic Interactions. Chin. J. Chem. Eng. 2009, 17(5), 781-790. 
(14) Fiorin, G.; Klein, M. L.; Henin, J. Using collective variables to drive molecular dynamics simulations. Mol. Phys. 2013, 111(22-23), 3345-3362.

(15) Plimpton, S. Fast Parallel Algorithms for Short-Range Molecular-Dynamics. J. Comput. Phys. 1995, 117(1), 1-19.

(16) Grimme, S. Semiempirical GGA-type density functional constructed with a long-range dispersion correction. J. Comput. Chem. 2006, 27(15), 1787-1799.

(17) Kresse, G.; Hafner, J. Abinitio Molecular-Dynamics for Liquid-Metals. Phys. Rev. B. 1993, 47(1), 558-561.

(18) Kresse, G.; Hafner, J. Ab-Initio Molecular-Dynamics Simulation of the Liquid-Metal Amorphous-Semiconductor Transition in Germanium. Phys. Rev. B. 1994, 49(20), 14251-14269.

(19) Kresse, G.; Furthmuller, J. Efficiency of ab-initio total energy calculations for metals and semiconductors using a plane-wave basis set. Comp. Mater. Sci. 1996, 6(1), 15-50.

(20) Kresse, G.; Furthmuller, J. Efficient iterative schemes for ab initio total-energy calculations using a plane-wave basis set. Phys. Rev. B. 1996, 54(16), 11169-11186.

(21) Blochl, P. E. Projector Augmented-Wave Method. Phys. Rev. B. 1994, 50(24), 17953-17979.

(22) Kresse, G.; Joubert, D. From ultrasoft pseudopotentials to the projector augmented-wave method. Phys. Rev. B. 1999, 59(3), 1758-1775.

(23) Fang, H. J.; Kamakoti, P.; Ravikovitch, P. I.; Aronson, M.; Paur, C.; Sholl, D. S. First principles derived, transferable force fields for $\mathrm{CO}_{2}$ adsorption in Na-exchanged cationic zeolites. Phys. Chem. Chem. Phys. 2013, 15(31), 12882-12894.

(24) Pulido, A.; Delgado, M. R.; Bludsky, O.; Rubes, M.; Nachtigall, P.; Arean, C. O. Combined DFT/CC and IR spectroscopic studies on carbon dioxide adsorption on the zeolite H-FER. Energy Environ. Sci. 2009, 2(11), 1187-1195.

(25) Arean, C. O.; Palomino, G. T.; Carayol, M. R. L.; Pulido, A.; Rubes, M.; Bludsky, O.; Nachtigall, P. Hydrogen adsorption on the zeolite Ca-A: DFT and FT-IR investigation. Chem. Phys. Lett. 2009, 477(1-3), 139-143.

(26) Darkrim, F.; Levesque, D. Monte Carlo simulations of hydrogen adsorption in single-walled carbon nanotubes. J. Chem. Phys. 1998, 109(12), 4981-4984.

(27) Pham, T. D.; Lobo, R. F. Adsorption equilibria of $\mathrm{CO}_{2}$ and small hydrocarbons in AEI-, CHA-, SIT-, and RRO-type siliceous zeolites. Microporous Mesoporous Mater. 2016, 236, 100108.

(28) Bai, P.; Tsapatsis, M.; Siepmann, J. I. TraPPE-zeo: Transferable potentials for phase equilibria force field for all-silica zeolites. J. Phys. Chem. C. 2013, 117(46), 24375-24387. 
(29) Martin, M. G.; Siepmann, J. I. Transferable potentials for phase equilibria. 1. United-atom description of n-alkanes. J. Phys. Chem. B. 1998, 102(14), 2569-2577.

(30) Wick, C. D.; Martin, M. G.; Siepmann, J. I. Transferable potentials for phase equilibria. 4. United-atom description of linear and branched alkenes and alkylbenzenes. J. Phys. Chem. B. 2000, 104(33), 8008-8016.

(31) Hill, J. R.; Sauer, J. Molecular mechanics potential for silica and zeolite catalysts based on ab initio calculations. 1. Dense and microporous silica. J. Phys. Chem. 1994, 98(4), 1238-1244.

(32) Granato, M. A.; Vlugt, T. J.; Rodrigues, A. E. Molecular simulation of propane- propylene binary adsorption equilibrium in zeolite 13X. Ind. Eng. Chem. Res. 2007, 46(22), 7239-7245.

(33) Fang, H.; Awati, R.; Boulfelfel, S. E.; Ravikovitch, P. I.; Sholl, D. S. First-principles-derived force fields for $\mathrm{CH}_{4}$ adsorption and diffusion in siliceous zeolites. J. Phys. Chem. C. 2018, 122(24), 12880-12891.

(34) Newsome, D. A.; Sholl, D. S. Predictive assessment of surface resistances in zeolite membranes using atomically detailed models. J. Phys. Chem. B. 2005, 109(15), 7237-7244.

(35) Liu, L.; Nicholson, D.; Bhatia, S. K. Interfacial resistance and length-dependent transport diffusivities in carbon nanotubes. J. Phys. Chem. C. 2016, 120(46), 26363-26373.

(36) Sellers, H.; Gislason, J. Adsorption and desorption rate constants for small molecules on metal surfaces: an example of Trouton's rule. Surf. Sci. 1999, 426(2), 147-153.

(37) Pranami, G.; Lamm, M. H. Estimating error in diffusion coefficients derived from molecular dynamics simulations. J. Chem. Theory Comput. 2015, 11(10), 4586-4592.

(38) Dutta, R. C.; Bhatia, S. K. Interfacial barriers to gas transport in zeolites: distinguishing internal and external resistances. Phys. Chem. Chem. Phys. 2018, 20(41), 26386-26395.

(39) Hafner, J.; Kresse, G., The vienna ab-initio simulation program vasp: An efficient and versatile tool for studying the structural, dynamic, and electronic properties of materials. In Properties of Complex Inorganic Solids, Springer: 1997; pp 69-82.

(40) Brown, W. M.; Wang, P.; Plimpton, S. J.; Tharrington, A. N. Implementing molecular dynamics on hybrid high performance computers-short range forces. Comput. Phys. Commun. 2011, 182(4), 898-911.

(41) Kresse, G.; Furthmüller, J. Efficient iterative schemes for ab initio total-energy calculations using a plane-wave basis set. Phys. Rev. B. 1996, 54(16), 11169.

(42) Dubbeldam, D.; Calero, S.; Ellis, D. E.; Snurr, R. Q. RASPA: molecular simulation software for adsorption and diffusion in flexible nanoporous materials. Mol. Simul. 2016, 42(2), 81-101.

(43) Tran, R.; Xu, Z.; Radhakrishnan, B.; Winston, D.; Sun, W.; Persson, K. A.; Ong, S. P. Surface energies of elemental crystals. Sci. Data. 2016, 3, 160080. 
(44) Larsen, A. H.; Mortensen, J. J.; Blomqvist, J.; Castelli, I. E.; Christensen, R.; Dułak, M.; Friis, J.; Groves, M. N.; Hammer, B.; Hargus, C. The atomic simulation environment-a Python library for working with atoms. J. Phys.: Condens. Matter. 2017, 29(27), 273002.

(45) Knio, O.; Medford, A. J.; Nair, S.; Sholl, D. S. Database of Computation-Ready 2D Zeolitic Slabs. Chem. Mater. 2018, 31(2), 353-364.

(46) MATLAB, R2016b (9.1.0.441655); The MathWorks Inc.: Natick, Massachusetts. 